\title{
A new formulation of equivalent effective stratospheric chlorine (EESC)
}

\author{
P. A. Newman ${ }^{1}$, J. S. Daniel ${ }^{2}$, D. W. Waugh ${ }^{3}$, and E. R. Nash ${ }^{4}$ \\ ${ }^{1}$ Atmospheric Chemistry and Dynamics Branch, NASA Goddard Space Flight Center, Greenbelt, MD, USA \\ ${ }^{2}$ NOAA Earth System Research Laboratory/Chemical Sciences Division, Boulder, CO, USA \\ ${ }^{3}$ Johns Hopkins University, Baltimore, MD, USA \\ ${ }^{4}$ Science Systems and Applications, Inc., Lanham, MD, USA
}

Received: 27 February 2007 - Published in Atmos. Chem. Phys. Discuss.: 22 March 2007

Revised: 20 August 2007 - Accepted: 21 August 2007 - Published: 3 September 2007

\begin{abstract}
Equivalent effective stratospheric chlorine (EESC) is a convenient parameter to quantify the effects of halogens (chlorine and bromine) on ozone depletion in the stratosphere. We show, discuss, and analyze a new formulation of EESC that now includes the effects of age-of-air dependent fractional release values and an age-of-air spectrum. This EESC can be more appropriately applied to various parts of the stratosphere because of this dependence on mean age-of-air. This new formulation provides quantitative estimates of EESC that can be directly related to inorganic chlorine and bromine throughout the stratosphere. In this paper, we first provide a detailed description of the EESC calculation. We then use this EESC formulation to estimate that human-produced ozone depleting substances will recover to 1980 levels in 2041 in the midlatitudes, and 2067 over Antarctica. These recovery dates are based upon the assumption that the international agreements for regulating ozone-depleting substances are adhered to. In addition to recovery dates, we also estimate the uncertainties and possible problems in the estimated times of recovery. The midlatitude recovery of 2041 has a $95 \%$ confidence uncertainty from 2028 to 2049, while the 2067 Antarctic recovery has a $95 \%$ confidence uncertainty from 2056 to 2078 . The principal uncertainties are from the estimated mean age-of-air and fractional release values, and the assumption that these quantities are time independent. Using other model estimates of age decrease due to climate change, we estimate that midlatitude recovery may be significantly accelerated.
\end{abstract}

Correspondence to: P. A. Newman

(paul.a.newman@nasa.gov)

\section{Introduction}

Ozone-depleting substances (ODSs) are primarily comprised of chlorine- and bromine-containing chemicals that have very long lifetimes in the atmosphere. These human produced ODSs have now been regulated under the landmark 1987 Montreal Protocol agreement and the amendments and adjustments to the Protocol (Sarma and Bankobeza, 2000). Based upon ground measurements and emission estimates, the future ground levels of ODSs have been developed as scenario A1 in Daniel et al. (2007). This scenario assumes that the Protocol will be adhered to and projects a steady decline of most ODSs over the coming decades.

Due to the established relationship between stratospheric ozone depletion and inorganic chlorine and bromine abundances, the temporal evolution of chlorine- and brominecontaining halogenated species is an important indicator of the potential damage of anthropogenic activity on the health of stratospheric ozone. Equivalent effective stratospheric chlorine (EESC) was developed to relate this halogen evolution to tropospheric source gases in a simple manner (Daniel et al., 1995). This quantity sums ODSs, accounting for a transit time to the stratosphere and for the greater potency of stratospheric bromine $(\mathrm{Br})$ compared to chlorine $(\mathrm{Cl})$ in its ozone destructiveness with a constant factor $(\alpha)$. It also includes the varying rates with which chlorine and bromine will be released in the stratosphere from different source gases (i.e., fractional release, $f$ ). The fractional release accounts for ODS dissociation in the stratosphere relative to the amount that entered at the tropopause. EESC has been used to relate predictions of human-produced ODS abundances to future ozone depletion (WMO, 1995, 1999, 2003, 2007).

Published by Copernicus Publications on behalf of the European Geosciences Union. 
In the past, EESC estimates have been used to evaluate various ODS emission scenarios primarily using two metrics. These are 1) a comparison of the times when EESC returns to 1980 levels or some later time and 2) the relative integrated changes in EESC between 1980 and when EESC returns to 1980 levels. These comparison metrics did not require that EESC quantitatively describe stratospheric chlorine and bromine levels, but only that it be proportional to these levels. Furthermore, these EESC calculations had not included a distribution of transport times from the troposphere into the stratosphere (the so called age-of-air spectrum) or any dependence of the fractional chlorine release values on the age-of-air. As air moves into the stratosphere at the tropical tropopause ODSs have not been dissociated, and have fractional release values near zero. In contrast, after transiting through the upper stratosphere, the ODSs in an air parcel are nearly fully dissociated and have fractional release values close to 1.0. Recently, Newman et al. (2006) reformulated EESC to account for both an age-of-air spectrum and age dependent fractional release values. This new formulation provides quantitative estimates of inorganic chlorine, bromine, fluorine, and EESC, for different regions of the stratosphere. The purpose of this paper is to further articulate this new formulation, to expose some of the uncertainties and assumptions in the calculation of EESC, and to compare this reformulated EESC to the "classic" EESC. These uncertainties and differences can have considerable impact on projected ODS recovery dates.

In addition to recovery estimates, EESC has been used as a proxy for halogen levels in ozone trend analysis studies (Yang et al., 2005; Dhomse et al., 2006; Guillas et al., 2006; Newman et al., 2006; Stolarski et al., 2006a). Past trend analysis studies used a linear trend to represent the effects of ODS changes, however with the regulation of ODSs, a linear trend is no longer appropriate. Most trend studies have used classic EESC (Yang et al., 2005; Dhomse et al., 2006; Guillas et al., 2006) as an ODS proxy because stratospheric ozone depletion trends are changing, and these changes most probably began when stratospheric halogen levels stopped increasing in the late 1990s (Anderson et al., 2000). A few of these studies have suggested that ozone recovery has now passed its first stage: i.e., the linear decrease has stopped and ozone levels are no longer dropping (e.g. Newchurch et al., 2003; Bodeker et al., 2007). It is critical that assumptions that are hidden, but implicit in EESC estimates, be understood in order to properly apply EESC in an ozone trend analysis and to ascribe ozone trend changes to the regulation of ODSs.

This paper is divided into six sections. Section 2 provides the theoretical description of EESC in both its new formulation and in the formulation used in past assessments. In the remainder of this paper, we will separately refer to the classic EESC used in the WMO assessments and to the reformulated EESC used by Newman et al. (2006). Section 3 shows a step-by-step construction of reformulated EESC, and Sect. 4 compares this reformulation to the classic EESC. Section 5 has detailed descriptions of reformulated EESC uncertainties. The final section summarizes and discusses the implications of reformulated EESC and its uncertainties.

\section{Equivalent effective stratospheric chlorine (EESC)}

EESC, as a function of time $t$, is defined as

$\operatorname{EESC}(t)=a\left(\sum_{C l} n_{i} f_{i} \rho_{i}+\alpha \sum_{B r} n_{i} f_{i} \rho_{i}\right)$,

where $n$ is the number of chlorine or bromine atoms of a particular source gas $i, f$ represents the efficiency of stratospheric halogen release of the source gas, and $\rho$ is the source gas mixing ratio in the stratosphere (Daniel et al., 1995). Summations are over the chlorine- and bromine-containing halocarbons. The leading factor, $a$, can be an arbitrary value (Solomon et al., 1995; Madronich et al., 1999; Prinn et al., 1999; Montzka et al., 2003; Clerbaux et al., 2007; Daniel et al., 2007), or it can be the fractional release value of chlorofluorocarbon-11 (CFC-11) so that the EESC quantity accurately represents the amount of inorganic chlorine $\left(\mathrm{Cl}_{\mathrm{y}}\right)$ and bromine $\left(\mathrm{Br}_{\mathrm{y}}\right)$ in some region of the stratosphere. In the rest of this manuscript, we use $a=1.0$. Equivalent effective chlorine (ECl) (Montzka et al., 1996) represents the same quantity as EESC but with no consideration of the transport time to the stratosphere.

In the classic EESC, $\rho_{i}$ is calculated assuming a simple time lag, $\Gamma$, from the surface observations

$\rho_{i}=\rho_{i, \text { entry }}(t-\Gamma)$,

where $\rho_{i, \text { entry }}(t)$ is the surface observation at time $t$. Many previous studies estimated this classic EESC assuming $\Gamma=3 \mathrm{y}$ to obtain a value appropriate for relating to globally averaged ozone loss (Solomon et al., 1995; Madronich et al., 1999; Prinn et al., 1999; Montzka et al., 2003; Clerbaux et al., 2007; Daniel et al., 2007).

The relative effectiveness of bromine compared to chlorine for ozone depletion ( $\alpha$ in Eq. 1), arises from the residence of inorganic bromine in more active compounds for ozone destruction, (e.g., BrO, see Daniel et al., 1999; Sinnhuber et al., 2006, for a complete description). This relative effectiveness is usually presented for global ozone depletion although it is a function of altitude, latitude, and background chlorine and bromine amount. We adopt a value of 60 for $\alpha$ in both EESC formulations following Daniel et al. (2007) and refer to the detailed discussion in that assessment regarding the update of this value from the value of 45 assumed by Montzka et al. (2003).

EESC estimates were reformulated by Newman et al. (2006). They revised the method of calculating EESC to account for the fact that 1) different stratospheric locations are characterized by different mean transit times, 2) each location is composed of air characterized by not a single transit 
time, but a range, and 3) the fractional release values depend on the mean age-of-air. Newman et al. (2006) calculated $\rho_{i}$ using age-of-air spectra weighted mixing ratios as

$\rho_{i}(t)=\int_{-\infty}^{t} \rho_{i, \text { entry }}\left(t^{\prime}\right) G\left(t-t^{\prime}\right) d t^{\prime}$

where $G(t)$ is the age-spectrum, and the fractional releases are age-of-air dependent, $f_{i}=f_{i}(\Gamma)$. This reformulation reduces to the classic EESC calculation if $G(t)=\delta(t-\Gamma)$, a delta function, and $\Gamma=3 \mathrm{y}$. This just represents a forward shift of the entire time series of $\rho_{i \text {,entry }}(t)$ by $3 \mathrm{y}$.

Estimates of total inorganic and organic chlorine and bromine can be provided from Eq. (1). The first term in Eq. (1) provides an estimate of $\mathrm{Cl}_{\mathrm{y}}$, while the second term (without $\alpha$ ) is an estimate of $\mathrm{Br}_{\mathrm{y}}$. Our estimate of $\mathrm{Br}_{\mathrm{y}}$ includes only halons and methyl bromide following Clerbaux et al. (2007) and Daniel et al. (2007). However, for quantitative estimates of $\mathrm{Cl}_{\mathrm{y}}$ and $\mathrm{Br}_{\mathrm{y}}$ an additional $100 \mathrm{ppt}$ of chlorine and 3-8 ppt of bromine ought to be included to account for very short lived containing substances (Law et al., 2007). Using our $\alpha$ value of 60, this would lead to an additional 280$580 \mathrm{ppt}$ contribution to EESC everywhere in the stratosphere. In addition to $\mathrm{Cl}_{\mathrm{y}}$ and $\mathrm{Br}_{\mathrm{y}}$, the reformulated equation can be used to estimate total inorganic fluorine by using the number of fluorine atoms in each species, and the same tropospheric mixing ratios and fractional release values.

In Eq. (1), $f$ represents the fraction of the species that has been dissociated during its movement through the stratosphere. Fractional release was originally defined by Solomon and Albritton (1992) as:

$f_{i}=\frac{\rho_{i}-\rho_{i, \phi, \theta}}{\rho_{i}}$,

where $\phi$ is latitude and $\theta$ represents altitude (or potential temperature). In Eq. (1), it is assumed that $f$ is constant in time for a given mean age-of-air. Schauffler et al. (2003) derived the fractional release of CFC-11 as a function of mean ageof-air from lower stratospheric aircraft observations. Observational based fractional release values for other species in the lower stratosphere were derived by Newman et al. (2006) using the same Schauffler et al. (2003) technique for CFC11 . The empirical fit equations for those release values versus age are from Newman et al. (2006).

Fractional release values are derived from observations of age-of-air, observations of a species, and the observations of the tropospheric trends of that same species (Schauffler et al., 2003). The mean age-of-air estimate uses observations of carbon dioxide $\left(\mathrm{CO}_{2}\right)$ (e.g. Andrews et al., 2001) or sulfur hexafluoride $\left(\mathrm{SF}_{6}\right)$ (e.g. Volk, et al., 1997). In our case, these observations were taken from NASA ER-2 field missions. The tropospheric trends are from Scenario Ab from Montzka et al. (2003). Following Schauffler et al. (2003), we apply an age spectrum to the tropospheric trend (see Eq. 3). The $f_{i}$ value is then calculated using the ER-2 species observation in

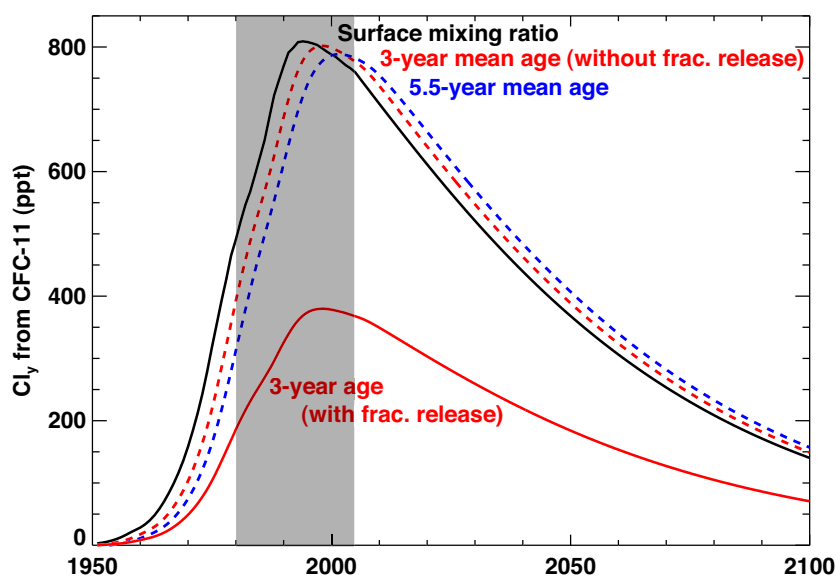

Fig. 1. CFC-11 as a function of year from scenario A1 of Daniel et al. (2007). CFC-11 contains three chlorine atoms, so all values have been multiplied by 3 . The black curve displays the surface concentration. The dashed red and blue curves show these CFC-11 values after an application of a 3-year age spectrum and a 5.5-year age spectrum, respectively. The solid red curve shows the CFC-11 contribution to $\mathrm{Cl}_{\mathrm{y}}$ after applying a $47 \%$ fractional release value to the dashed red curve. The fractional release for a 5.5-year age spectrum is $99 \%$, so the resulting curve overlays the dashed blue curve. The gray area indicates where values are based on measurements.

Eq. (4). Finally, a fit is made to all of the calculated fractional release values vs. mean age (Newman et al., 2006).

To apply Eq. (3) to Eq. (1) it is necessary to know the mean age-of-air and, in the case of Eq. (3), the age spectrum. Observations indicate that in the lower stratosphere the mean age is around $3 \mathrm{y}$ in midlatitudes and around $5.5 \mathrm{y}$ in polar regions (e.g., Waugh and Hall, 2002; Newman et al., 2006, and references therein), and we use these values in our standard calculations. There is some uncertainty in the characteristics of the full age spectrum, although analyses of measurements and model calculations of multiple tracers indicates that the spectra are broad (e.g., Andrews et al., 2001; Schoeberl et al., 2005). In our calculations we assume that the age spectrum is an inverse Gaussian function with mean, $\Gamma$, and width, $\Delta$ (see Eq. 9 of Waugh and Hall, 2002), related by $\Delta=\Gamma / 2$. The sensitivity to this value of $\Delta / \Gamma$ is examined below.

\section{Estimating EESC}

In this section, we will show the details of estimating the reformulated EESC. We start with a time history of CFC-11 mixing ratio measurements and expected future concentrations. Figure 1 displays this CFC-11 time history of chlorine using scenario A1 of Daniel et al. (2007). The surface observations and estimates (black) of the chlorine contained in CFC-11 are multiplied by 3 to account for the three chlorine atoms $\left(n_{i} \rho_{i}\right.$ in Eq. 1). The peak CFC-11 surface 
Table 1. Fractional release values for all 16 species used in this study for 3-year and 5.5-year mean age-of-air. The mean surface mixing ratio is for 2000 (Daniel et al., 2007). The sensitivity of the peak EESC value and the recovery year, relative to 1980 EESC values, are for a change in $f$ of 0.10 about the indicated value.

\begin{tabular}{|c|c|c|c|c|c|c|c|c|}
\hline \multirow[t]{2}{*}{ Species } & \multirow[t]{2}{*}{ Formula } & \multirow{2}{*}{$\begin{array}{c}\text { Mean surface } \\
\text { mixing ratio } \\
{\left[\rho_{i, \text { entry }}\right]} \\
(\mathrm{ppt})\end{array}$} & \multicolumn{3}{|c|}{$\Gamma=3 \mathrm{y}$} & \multicolumn{3}{|c|}{$\Gamma=5.5 \mathrm{y}$} \\
\hline & & & $\begin{array}{l}\text { Fractional } \\
\text { release }[f]\end{array}$ & $\begin{array}{c}\text { Peak } \\
\text { EESC } \\
\text { (ppt) }\end{array}$ & $\begin{array}{c}\text { Recovery } \\
\text { year } \\
\text { (y) }\end{array}$ & $\begin{array}{l}\text { Fractional } \\
\text { release }[f]\end{array}$ & $\begin{array}{c}\text { Peak } \\
\text { EESC } \\
(\mathrm{ppt})\end{array}$ & $\begin{array}{c}\text { Recovery } \\
\text { year } \\
\text { (y) }\end{array}$ \\
\hline CFC-11 & $\mathrm{CCl}_{3} \mathrm{~F}$ & 262.6 & 0.47 & 79.9 & 0.47 & 0.99 & 78.8 & -0.07 \\
\hline CFC-12 & $\mathrm{CCl}_{2} \mathrm{~F}_{2}$ & 538.0 & 0.23 & 102.0 & 2.59 & 0.86 & 103.2 & 1.21 \\
\hline CFC-113 & $\mathrm{CCl}_{2} \mathrm{FCClF}_{2}$ & 82.3 & 0.29 & 24.1 & 0.91 & 0.90 & 23.9 & 0.42 \\
\hline CFC-114 & $\mathrm{CClF}_{2} \mathrm{CClF}_{2}$ & 17.0 & 0.12 & 3.3 & 0.09 & 0.40 & 3.3 & 0.05 \\
\hline CFC-115 & $\mathrm{CClFCF}_{3}$ & 8.73 & 0.04 & 0.7 & 0.06 & 0.15 & 0.8 & 0.04 \\
\hline Carbon tetrachloride & $\mathrm{CCl}_{4}$ & 98.8 & 0.56 & 41.5 & -1.77 & 1.00 & 40.7 & -1.37 \\
\hline Methyl chloroform & $\mathrm{CH}_{3} \mathrm{CCl}_{3}$ & 49.9 & 0.67 & 35.3 & -1.29 & 0.99 & 26.8 & -0.58 \\
\hline HCFC-22 & $\mathrm{CHClF}_{2}$ & 139.8 & 0.13 & 10.6 & 2.36 & 0.41 & 11.7 & 0.33 \\
\hline HCFC-141b & $\mathrm{CH}_{3} \mathrm{CCl}_{2} \mathrm{~F}$ & 11.9 & 0.08 & 0.3 & 0.40 & 0.90 & 1.1 & 0.12 \\
\hline HCFC-142b & $\mathrm{CH}_{3} \mathrm{CClF}_{2}$ & 11.6 & 0.01 & 0.5 & 0.06 & 0.29 & 0.7 & 0.01 \\
\hline Halon-1211 & $\mathrm{CBrClF}_{2}$ & 4.0 & 0.62 & 18.7 & 0.61 & 1.00 & 20.5 & 0.10 \\
\hline Halon-1202 & $\mathrm{CBr}_{2} \mathrm{~F}_{2}$ & 0.05 & 0.62 & 0.4 & -0.01 & 1.00 & 0.5 & 0.00 \\
\hline Halon-1301 & $\mathrm{CBrF}_{3}$ & 2.7 & 0.28 & 12.8 & 1.19 & 0.80 & 14.0 & 0.57 \\
\hline Halon-2402 & $\mathrm{CBrF}_{2} \mathrm{CBrF}_{2}$ & 0.41 & 0.65 & 4.7 & 0.02 & 1.00 & 4.8 & -0.01 \\
\hline Methyl bromide & $\mathrm{CH}_{3} \mathrm{Br}$ & 8.9 & 0.60 & 55.8 & -0.51 & 0.99 & 55.0 & -0.27 \\
\hline Methyl chloride & $\mathrm{CH}_{3} \mathrm{Cl}$ & 550.0 & 0.44 & 55.0 & 0.02 & 0.91 & 55.0 & 0.03 \\
\hline
\end{tabular}

value of $809.1 \mathrm{ppt}$ of chlorine occurs in 1994 shortly after the 1992 production phaseout during the 1993-1994 period (Daniel et al., 2007). The figure also shows the chlorine from CFC-11 after the application of a 3-year age spectrum ( $\Gamma=3 \mathrm{y}, \Delta=1.5 \mathrm{y}$, red dashed) and a 5.5 -year age spectrum ( $\Gamma=5.5 \mathrm{y}, \Delta=2.75 \mathrm{y}$, blue dashed) to the surface time series using Eq. (3). The age spectrum shifts the time series to later times as would be expected. While the surface CFC-11 peaked in 1994, the CFC-11 in the stratosphere for 3-year old air peaked in 1998. For 5.5-year old air, the peak is shifted to 2001 and the maximum is reduced to about $788 \mathrm{ppt}$. This shift is slightly later than that obtained from a simple 5.5-year shift and the peak is smaller than the surface peak because of the consideration of the age spectrum. The peak value in 2001 results from the 5.5-year age spectrum weighted average of surface values prior to 2001. Since most of those surface values are considerably less than the $809.1 \mathrm{ppt}$ peak, the peak in 2001 must be smaller than the size of the surface peak.

The fractional release, $f$, provides the fractional amount of CFC-11 that has been dissociated in the stratosphere relative to the amount that entered at the tropopause. Schauffler et al. (2003) used ER-2 observations to calculate the fractional release of $\mathrm{CFC}-11$ as a function of mean age-of-air. The release of chlorine via the degradation of CFC-11 in the stratosphere occurs by solar photolysis at wavelengths less than approximately $240 \mathrm{~nm}$. At the tropical tropopause (air that has recently entered the stratosphere), virtually none of the CFC-11 has been degraded. Hence, its fractional release is zero. For a 3-year mean age-of-air, approximately $47 \%$ of the CFC-11 has been converted into inorganic chlorine, with $53 \%$ remaining as CFC-11. For a 5.5-year mean age-of-air, essentially all of the CFC-11 has been converted. The solid red curve of Fig. 1 displays the $\mathrm{Cl}_{\mathrm{y}}$ contribution from CFC$11\left(n_{i} f_{i} \rho_{i}\right.$ in Eq. 1).

Table 1 lists 16 different species used to estimate EESC in this study along with their chemical formulas, year 2000 surface mixing ratios from Daniel et al. (2007) scenario A1, and observationally derived fractional release values for 3and 5.5-year mean ages (valid in the lower stratosphere).

$\mathrm{Cl}_{\mathrm{y}}$ is estimated by summing the contributions of all the long-lived chlorine species. Short-lived chlorine containing gases may contribute approximately $100 \mathrm{ppt}$ to $\mathrm{Cl}_{\mathrm{y}}(\mathrm{Law}$ et al., 2007), but their contribution is not included herein. Figure 2 displays the contributions from CFC-11, CFC-12, and methyl chloroform to total chlorine. Figure 2a is identical to Fig. 1, shown again for ease of comparison with CFC12 and methyl chloroform. Figures $2 \mathrm{a}-\mathrm{c}$, show surface concentrations (black), the inorganic contribution to $\mathrm{Cl}_{\mathrm{y}}$ for a 3 -year mean age-of-air (filled), and the inorganic contribution to $\mathrm{Cl}_{\mathrm{y}}$ for a 5.5-year mean age-of-air (dashed). The cumulative sum is shown in Fig. 2 d. On a time average, the anthropogenic species that contribute the majority of the chlorine to the stratospheric inorganic burden are: CFC11, CFC-12, carbon tetrachloride, methyl chloroform, CFC113, and HCFC-22. Methyl chloride is the dominant natural species that contributes to stratospheric chlorine. An additional five chlorine-containing species are included in 
(a) CFC-11

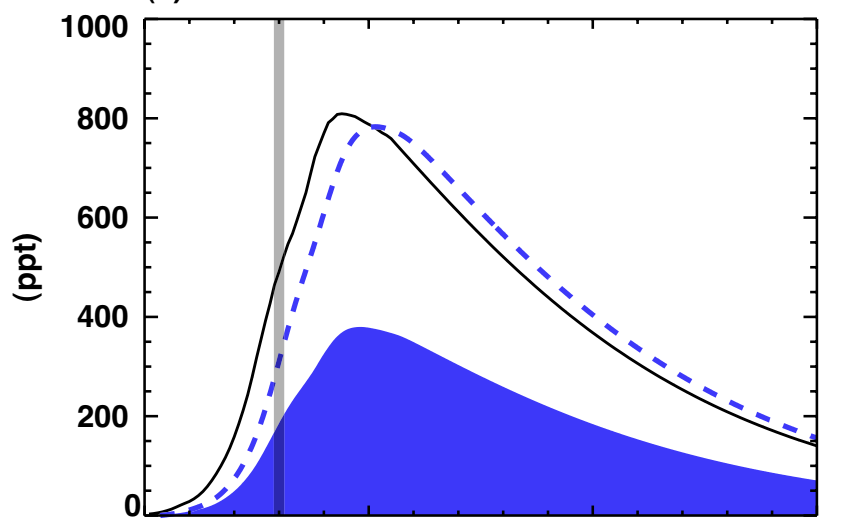

(c) $\mathrm{CH}_{3} \mathrm{CCl}_{3}$

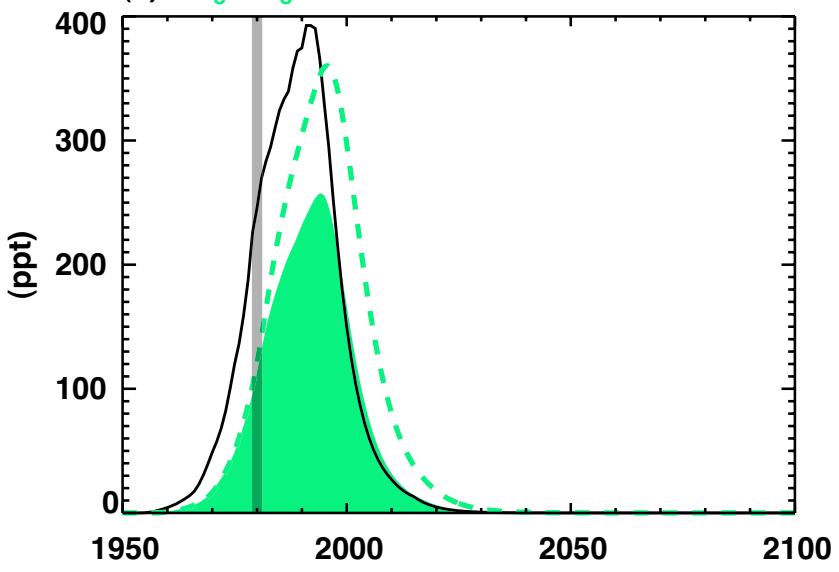

(b) $\mathrm{CFC}-12$

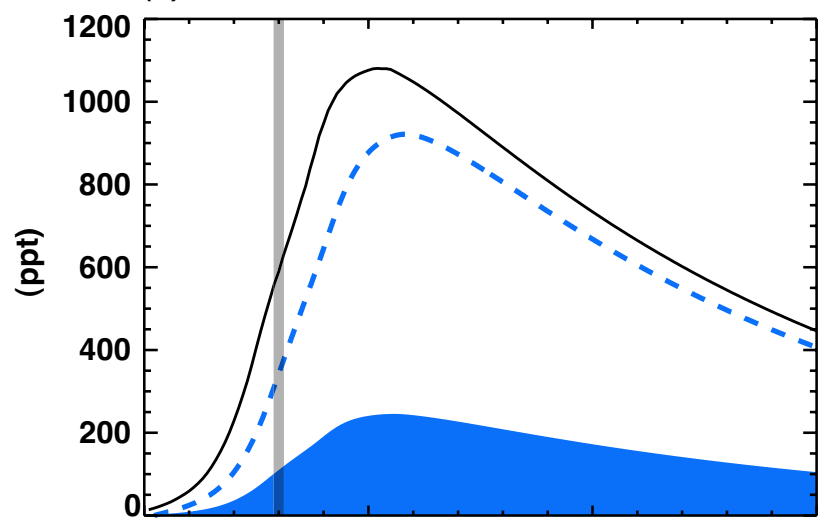

(d) Cly

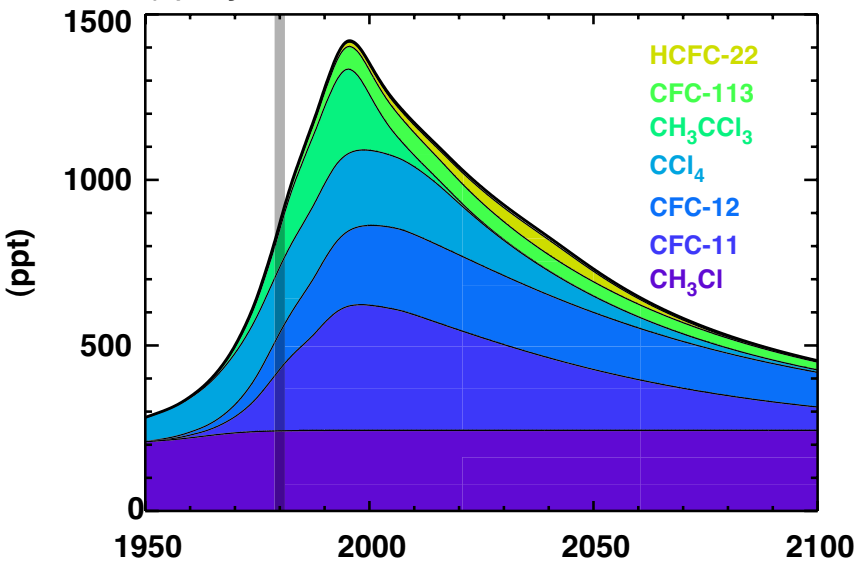

Fig. 2. Chlorine species as a function of year for (a) CFC-11 (as in Fig. 1), (b) $\mathrm{CFC}-12$, and (c) methyl chloroform $\left.\left(\mathrm{CH}_{3} \mathrm{CCl}\right)_{3}\right)$ The black curve represents the surface chlorine for each species (i.e., surface measurement scaled by the number of chlorine atoms). Filled color curves (dashed lines) represent the chlorine concentrations with fractional release for a 3-year (5.5-year) mean age-of-air. (d) $\mathrm{Cl}_{\mathrm{y}}$ as a function of year for a 3-year mean age-of-air. The filled color curves represent the summed contributions of each species to $\mathrm{Cl}_{\mathrm{y}}$. The gray vertical line indicates the reference year of 1980 .

Fig. 2d (see Table 1), but their contributions are too small to be clearly displayed. For air in the stratosphere with a 3year mean age-of-air, $\mathrm{Cl}_{\mathrm{y}}$ had a peak value in mid-1995 at approximately 1420 ppt.

For a 3-year mean age, the associated fractional releases for CFC-11, CFC-12 and methyl chloroform are 0.47, 0.23, and 0.67 , respectively (Table 1), while for a 5.5-year mean age the values are $0.99,0.86$, and 0.99 . The fractional release values of nearly all of the species approach a value of 1.0 for the longer ages $(>5.5 \mathrm{y})$. The larger fractional release values occur because the older air has typically been lofted into the middle and upper stratosphere where species are more easily photolyzed or oxidized.

Comparisons of these $\mathrm{Cl}_{\mathrm{y}}$ estimates to other observational based estimates have been made by Newman et al. (2006) and Lary et al. (2007) ${ }^{1}$. Newman et al. (2006) used Halogen

\footnotetext{
${ }^{1}$ Lary, D. J., Waugh, D. W., Douglass, A. R., Stolarski, R. S.,
}

Occultation Experiment (HALOE) observed maximum $\mathrm{HCl}$ values in the Antarctic vortex to show a reasonable comparison to both the magnitude and timing of the $\mathrm{Cl}_{\mathrm{y}}$. Lary et al. (2007) ${ }^{1}$ used a neural network applied to a series of satellite chlorine observations to derive $\mathrm{Cl}_{\mathrm{y}}$ estimates in various parts of the stratosphere. Their Fig. 3 showed an excellent comparison of the $\mathrm{Cl}_{\mathrm{y}}$ evolution and magnitude for appropriate mean age-of-air estimates.

As indicated in Eq. (1), EESC is estimated by combining the inorganic chlorine with inorganic bromine. Bromine is a more efficient depleter of ozone, and is scaled by $\alpha=60$. Figure 3 displays $\mathrm{Cl}_{\mathrm{y}}, \mathrm{Br}_{\mathrm{y}}$, and EESC from long-lived source gases. Figure $3 \mathrm{a}$ is the same as Fig. $2 \mathrm{~d}$ (with color rearrangement) for a 3-year mean age-of-air. $\mathrm{Br}_{\mathrm{y}}$ peaks in 2001, about

Newman, P. A., and Mussa, H.: Variations in stratospheric inorganic chlorine between 1991 and 2006, Geophys. Res. Lett., in review, 2007. 
(a) Cly (3-year mean age)

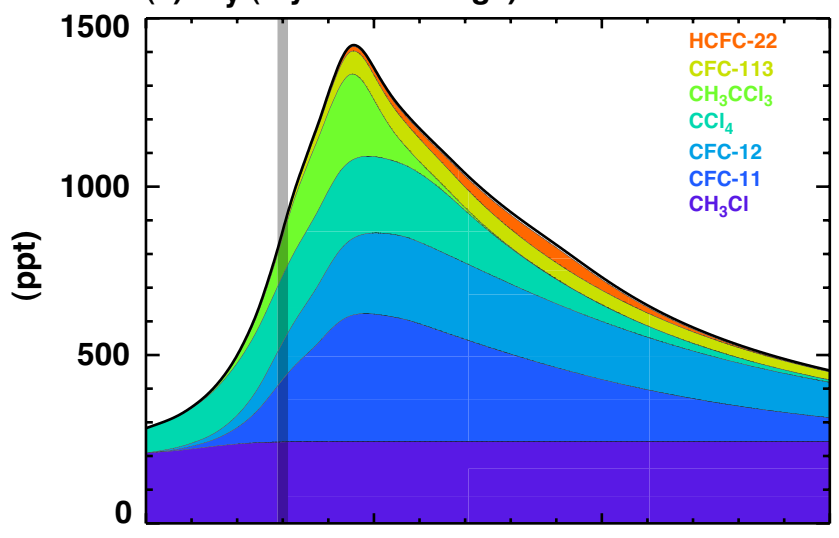

(c) EESC (3-year mean age)

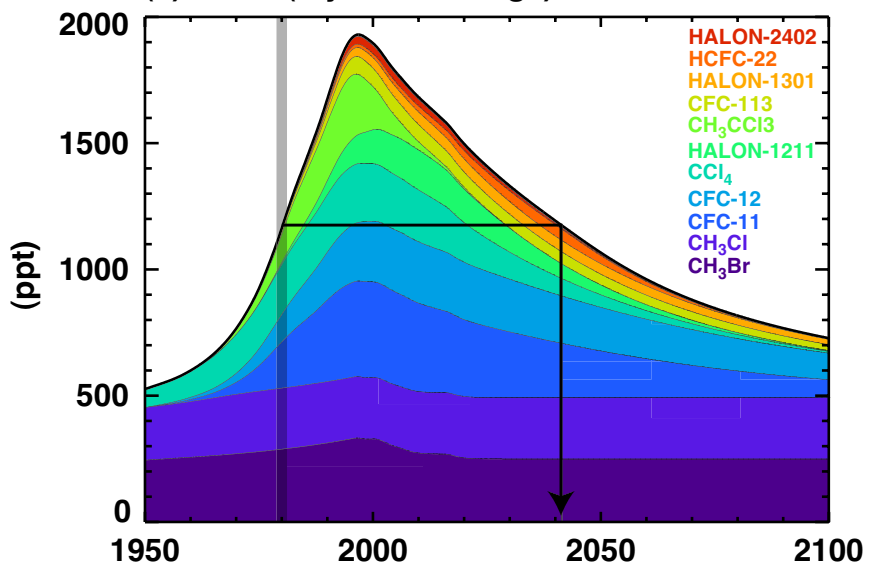

(b) Bry (3-year mean age)

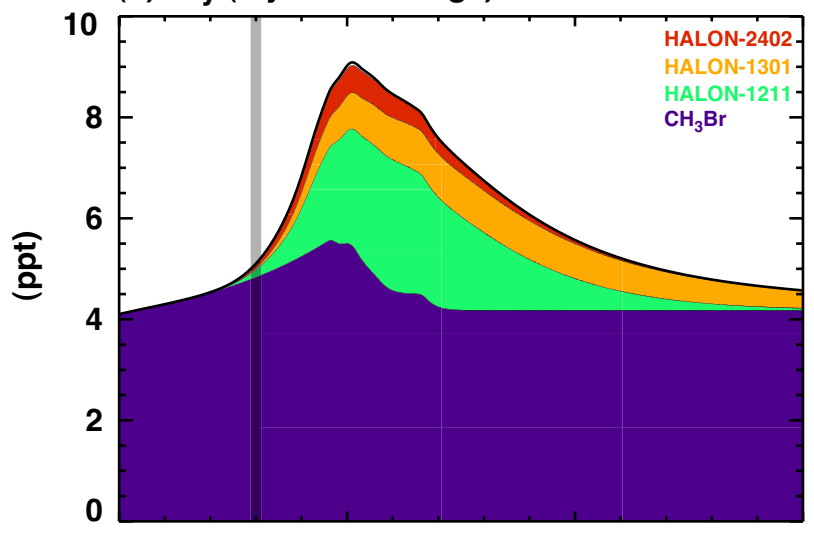

(d) EESC (5.5-year mean age)

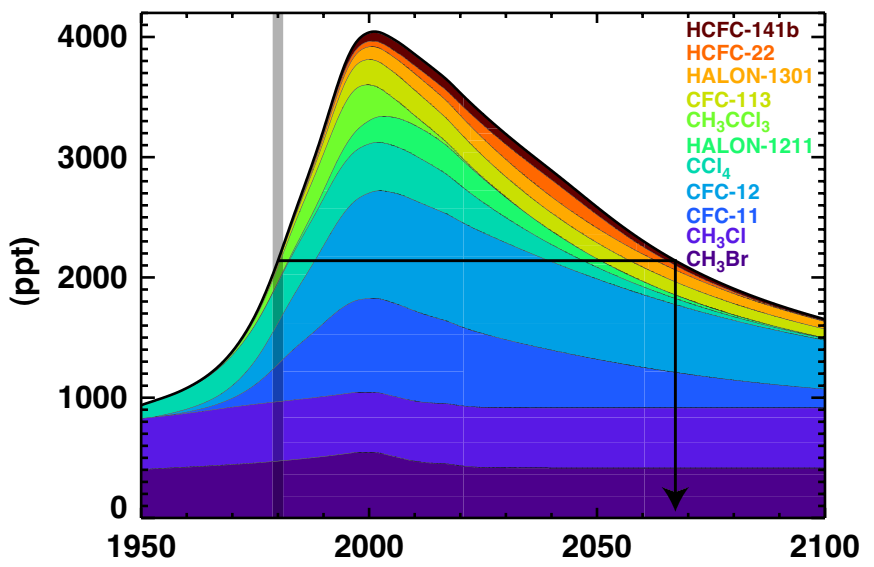

Fig. 3. (a) Inorganic chlorine, (b) inorganic bromine, and (c) EESC versus time for a 3-year mean age-of-air. (d) EESC versus time for a 5.5-year mean age-of-air. The filled color curves represent the summed contributions of each species to the total. Although all species are included in the total, only those that contribute more than $0.5 \%$ to the total are shown separately. The gray vertical line indicates the reference year of 1980. The black horizontal and vertical lines indicate the recovery date of EESC to 1980 values.

six years later than $\mathrm{Cl}_{\mathrm{y}}$, with a maximum value of $9.1 \mathrm{ppt}$. Following Law et al. (2007), the $\mathrm{Br}_{\mathrm{y}}$ should include a uniform offset of 3-8 ppt to account for very short-lived species (VSLSs). Bry estimates have been made by Dorf et al. (2006) using Differential Optical Absorption Spectroscopy (DOAS) observations of $\mathrm{BrO}$. For air with a 5- to 6-year mean age, they estimate $21.5 \mathrm{ppt}$ of $\mathrm{Br}_{\mathrm{y}}$ in the stratosphere for the period. Our lower stratospheric concentrations are inconsistent with this estimate, since we do not include any contribution from VSLSs and our $\mathrm{Br}_{\mathrm{y}}$ is estimated for the midlatitude lower stratosphere with a 3-year mean age-of-air where the fractional release values are all less than 1.0 (see bromine species in Table 1). For the upper stratosphere with a mean age of $5.5 \mathrm{y}$, we estimate a $\mathrm{Br}_{\mathrm{y}}$ peak of $15.4 \mathrm{ppt}$ in 2004, consistent with Dorf et al. (2006) if an age shift and an additional 3-8 ppt is added to account for VSLSs.

The reformulated EESC in Fig. $3 c$ is combined from Figs. 3a and b. Figure 3d is similar to Fig. 3c, but is calculated for a 5.5-year mean age-of-air.
The EESC is characterized by both a strong variation of magnitude and peak year between the 3-year curve (Fig. 3c) and the 5.5-year curve (Fig. 3d). The reference year of 1980 is often chosen as a metric for substantial recovery (gray vertical line). The year of recovery (black vertical line) of EESC is then considered to be when the EESC value drops to the same as it was in the reference year (black horizontal line). This recovery of EESC would occur in 2041.2 for a 3-year (Fig. 3c) and in 2067.2 for a 5.5-year (Fig. 3d) mean ageof-air. The peak values of EESC are substantially different between a 3- and a 5.5-year mean age. The 3-year mean age EESC value peaks at $1931 \mathrm{ppt}$ in mid-1996, while the 5.5year mean age EESC peaks at a value of 4045 ppt in early 2001. 


\section{Comparison with classic EESC}

The classic EESC (Solomon et al., 1995; Madronich et al., 1999; Prinn et al., 1999; Montzka et al., 2003; Clerbaux et al., 2007; Daniel et al., 2007) is formulated as shown in Eq. (1), but it uses the simple time series shift noted above and uses different fractional release values than are estimated by Schauffler et al. (2003) and used by Newman et al. (2006). Figure 4 displays the EESC estimated in the reformulation (solid) and the classic technique (dashed) using $\Gamma=3$ y (blue) and $\Gamma=5.5 \mathrm{y}$ (red). Figure $4 \mathrm{a}$ shows the actual values of EESC as calculated by the two techniques, where the reformulated EESC curves yield a quantitative estimate (i.e., $\mathrm{Cl}_{\mathrm{y}}$ and $\mathrm{Br}_{\mathrm{y}}$ ) while the classic EESC does not.

Figure $4 \mathrm{~b}$ shows the EESC curves normalized to the respective peak values. For $\Gamma=3 \mathrm{y}$, the classic EESC behavior is similar to the reformulated EESC. However, for $\Gamma=5.5 \mathrm{y}$, there is a significant difference between reformulated and classic EESC in the period after approximately 2001. This difference results from the higher "relative to 1980" peak value of the classic EESC in 2000 that can be seen in Fig. 4c.

As noted in Table 1, differing fractional release values will impact the estimated recovery date. Because of these release differences, recovery estimates here are different from those reported by Daniel et al. (2007). For a 3-year shift in the classic EESC, Daniel et al. (2007) estimated a 2048.8 recovery in comparison to our reformulated EESC estimate of 2041.2 (a difference of $7.6 \mathrm{y}$ ). Only a small part of this difference is due the application of an age spectrum: if we use the simple 3-year shift, rather than an age spectrum, with our age dependent release values the difference from Daniel et al. (2007) is 7.0 y. For a 6-year shift, Daniel et al. (2007) calculated a 2064.7 recovery. If we use their 6-year mean age with our reformulated EESC, we estimate recovery in 2073.3. Hence, recovery differences between our estimates and Daniel et al. (2007) are primarily related to fractional release value differences.

The reasons for the differences between our reformulated EESC fractional release values (Schauffler et al., 2003; Newman et al., 2006) and the Montzka et al. (2003), Clerbaux et al. (2007), and Daniel et al. (2007) release values are currently uncertain. There are particularly striking differences in the values for HCFC-141b and HCFC-142b. The derivation of these values from data (Schauffler et al., 2003) is quite sensitive to an accurate assessment of the age-of-air for gases such as these with a large trend. However, the uncertainty in the age inferred by Schauffler et al. (2003) is unlikely to explain the large differences. On the other hand, the values adopted by Montzka et al. (2003), Clerbaux et al. (2007), and Daniel et al. (2007) are taken from Solomon and Albritton (1992) and were calculated with a 2-D model. It also seems unlikely that the kinetics of these gases, combined with transport uncertainties of the model would lead to such fractional release errors. The resolution of the differences in these values will require both new observations and a dedicated study.
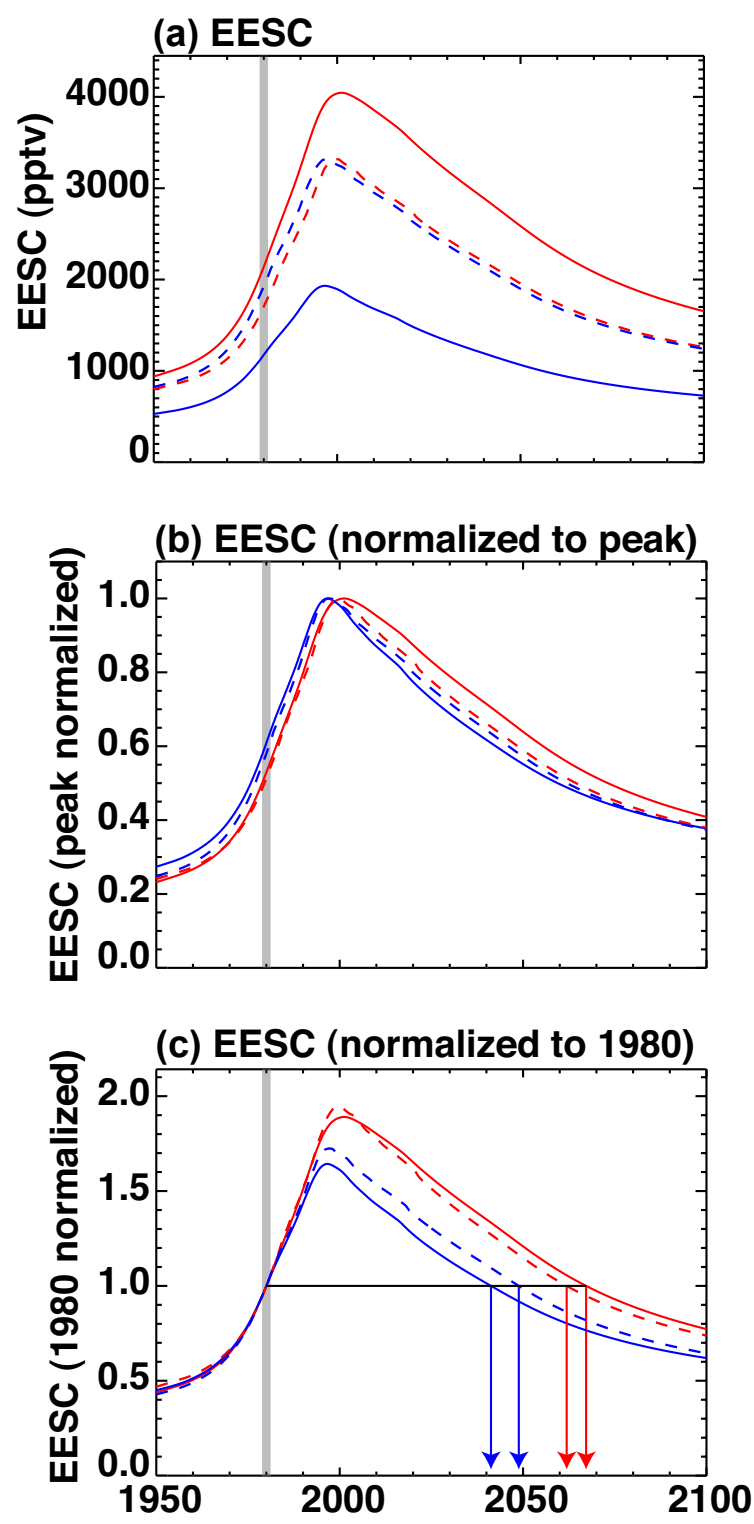

Fig. 4. (a) Actual EESC calculations, (b) EESC normalized to the peak value, and (c) EESC normalized to the 1980 value versus time. The blue and red curves indicate a 3-year and 5.5-year mean age-ofair, respectively. The solid curves are the reformulated EESC. The dashed curves show the classic EESC as used by Clerbaux et al. (2007) and Daniel et al. (2007) with the exception that a 5.5-year shift is used instead of a 6-year shift. The gray vertical line indicates the reference year of 1980 . The black horizontal line along with the blue and red vertical lines indicate the recovery date of EESC to 1980 values.

Because we are primarily interested in exploring the sensitivities of EESC, for the purpose of this work we will rely on the fractional release values presented by Newman et al. (2006), while at the same time acknowledging the important degree of uncertainty in both sets of fractional release values. 


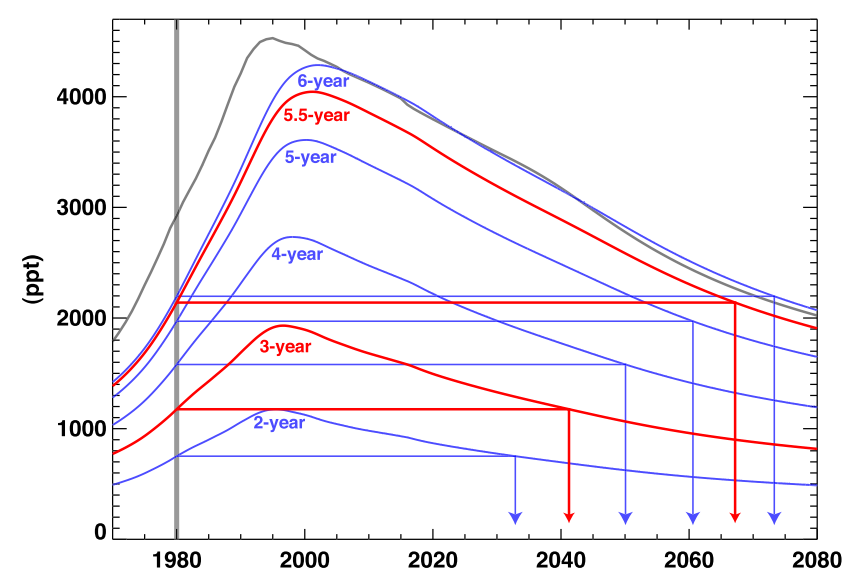

Fig. 5. EESC and ECl versus time. The blue curves are for EESC with mean age-of-air values of 2, 4, 5, and $6 \mathrm{y}$. The red curves indicate the 3-year and 5.5-year EESC calculations. The gray curve shows ECl. The gray vertical line indicates the reference year of 1980. The blue and red horizontal and vertical lines indicate the recovery date of EESC to 1980 values.

\section{$5 \quad$ EESC sensitivities and uncertainties}

The calculations of EESC shown in Fig. 1 through Fig. 4 involved the choice of several parameter values, some of which are uncertain. We now examine the sensitivity of the EESC calculations and recovery dates to the mean age-of-air, the age spectrum width, the choice of $\alpha$, the scenario, the fractional release value uncertainties, the choice of 1980 as the start date, and the assumption that the mean age-of-air is a constant in time.

\subsection{Sensitivity to mean age-of-air}

EESC is strongly dependent on the mean age-of-air. Mean age-of-air impacts both the temporal behavior of EESC and the peak concentration of EESC. Figure 5 displays the EESC for a variety of mean age-of-air values ranging from 2 to $6 \mathrm{y}$. As noted above in Fig. 1, the peak shifts to the right for older mean age. $\mathrm{ECl}$ (gray curve) indicates the peak values at the surface and is computed from the observations using $\alpha=60$. $\mathrm{ECl}$ peaks at about $4529 \mathrm{ppt}$ around the beginning of 1995 .

EESC is also characterized by a strong variation of magnitude and peak year as a function of mean age-of-air. For ages greater than 6 years, there are small changes in the magnitude of EESC, since almost all of the ODS species have been converted to $\mathrm{Cl}_{\mathrm{y}}$ and $\mathrm{Br}_{\mathrm{y}}$, however, the peaks continue to shift towards later dates for these older ages.

In stratospheric ozone recovery discussions, it is first necessary to understand the stratospheric chlorine and bromine temporal evolution. A larger mean age-of-air leads to a later recovery date because a larger age implies that the stratospheric EESC level was relatively lower in 1980 with respect (a) EESC Peak Value
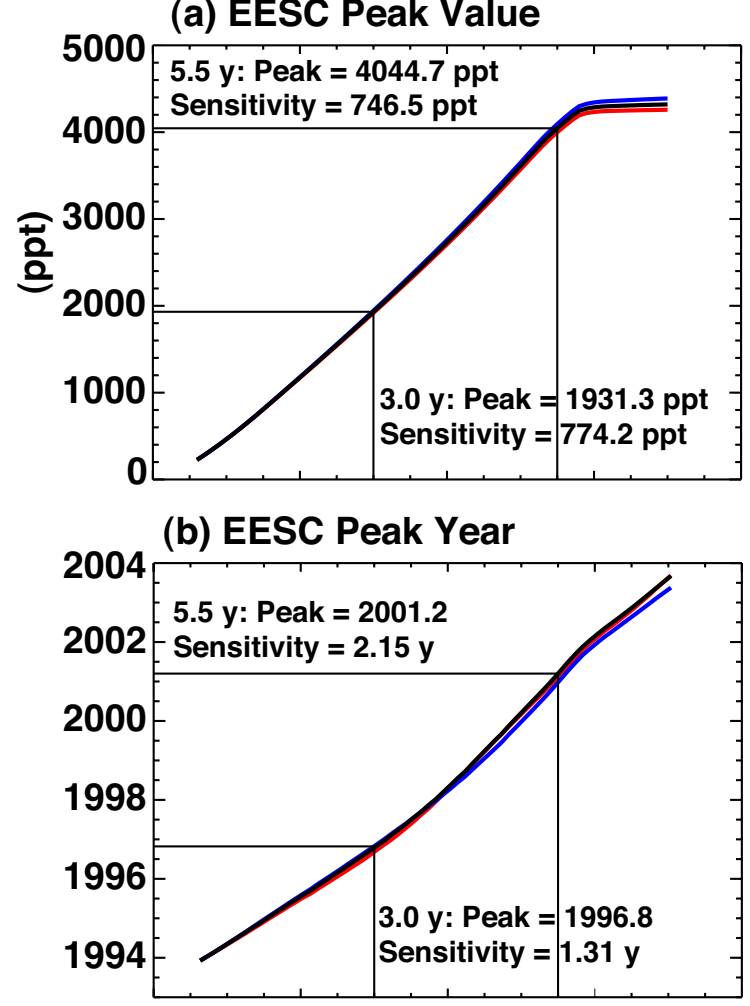

(c) EESC RecoveryYear

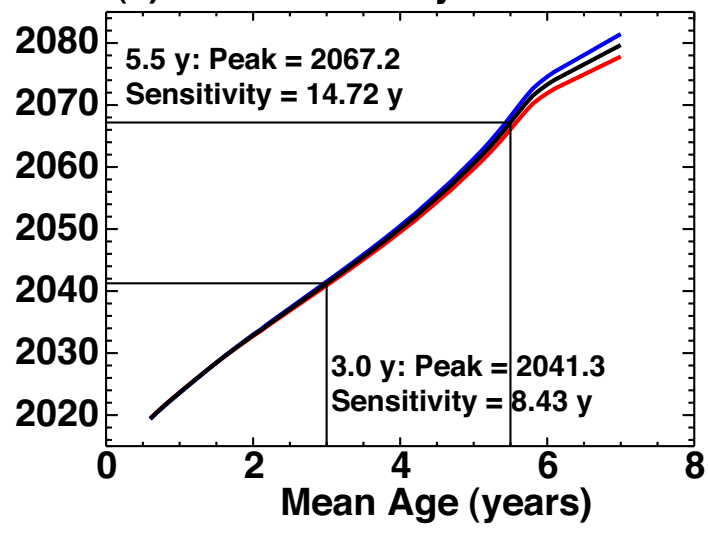

Fig. 6. (a) EESC peak value, (b) EESC peak year, and (c) EESC recovery year versus mean age-of air. The black curve represents the standard calculation. The red and blue curves indicate a spectral width that has been increased and decreased by $30 \%$, respectively, as compared to that of the standard calculation. The black horizontal and vertical lines indicate the associated values for a mean of 3 and $5.5 \mathrm{y}$.

to the peak EESC that occurred in the late 1990 to early 2000 period. Therefore, the return to that lower level will take longer. The 3-year mean age implies an EESC recovery near 2041, while the older 5.5-year mean age implies a recovery near 2067. Figure 6a displays the peak EESC value versus 
age-of-air (black). The EESC peak is very sensitive to mean age-of-air, and increases from zero for a zero mean age to $4045 \mathrm{ppt}$ for a 5.5-year mean age. This increase results from the competition between the fractional release, which results in more liberated chlorine and bromine as the age increases, and the greater flattening of the peak arising from the larger age spectrum width as the age increases. For mean ages above about $5.8 \mathrm{y}$, nearly all of the organic species have been degraded, so little additional chlorine or bromine is available for release. Figure $6 \mathrm{~b}$ shows the peak year versus mean ageof-air (black). The peak year varies almost linearly with age. Each additional year of age results in approximately a 1.0- to 1.5 -year increase in the peak year. The asymmetries in the EESC time series and the consideration of the age spectrum are the reasons the increase is not exactly $1.0 \mathrm{y}$.

Recovery is very sensitive to mean age-of-air (Newman et al., 2006). Figure $6 \mathrm{c}$ shows the recovery year versus mean age-of-air (black). Each additional year of age results in approximately a 10-year delay of the recovery. This large recovery sensitivity to mean age-of-air can be understood by examining Fig. 4c. Because of the large age, relative EESC for a 5.5-year mean age (appropriate to the Antarctic polar vortex) continues to grow during the 1995-2001 period, reaching a value that is nearly double its 1980 value. The relative EESC for a 3-year mean age (appropriate for the midlatitudes) only increases an additional 66\% from 1980 to 1996. Because the decay rates (post 2001) for these relative EESC curves are similar, the EESC for 3-year air recovers much earlier than for 5.5-year air.

\subsection{Sensitivity to width}

In our calculations of the age spectra, we have assumed that the age spectrum width is half of the mean age-of-air $(\Delta=\Gamma / 2)$. This is used in all of Fig. 1 through Fig. 5. We test the sensitivity to the spectral width by applying simple increases and decreases to the width. This has no effect on the fractional release values used because they are determined from the mean age alone. In Fig. 6, the spectral width has been both increased (red) and decreased (blue) by $30 \%$. For example, the 5.5-year age spectrum width has been varied from $1.9 \mathrm{y}$ to $3.6 \mathrm{y}$. The largest differences for the peak EESC value and recovery year occur for the largest ages. However, even then the values are not very sensitive to variations in $\Delta$ for any of the three metrics. For a 5.5-year mean age, the peak value decreases by only $46 \mathrm{ppt}(1.1 \%$ of the $4045 \mathrm{ppt}$ value) with a $30 \%$ increase of the spectrum width of $0.8 \mathrm{y}$. The peak year and the recovery year also demonstrate small variations for large width variations. For a 5.5-year mean age-of-air, increasing the width by $30 \%$ advances (or hastens) the date of recovery by $1.1 \mathrm{y}$ (2067.2 to 2066.1), while decreasing the width by $30 \%$ delays the recovery by $1.0 \mathrm{y}$ to 2068.2. In summary, in contrast to variations in mean age the EESC is only moderately sensitive to variations in the spectrum width.

\subsection{Sensitivity to $\alpha$}

Because the bromine catalytic cycle is more efficient for ozone loss than the chlorine catalytic cycle, the $\mathrm{Br}_{\mathrm{y}}$ contribution to EESC is scaled $(\alpha=60)$ to account for this efficiency. Model estimates of $\alpha$ show variations with time, altitude, and latitude (e.g., Daniel et al., 1999). Inspection of Fig. 5 of Daniel et al. (1999) shows a variation of $\alpha$ from a minimum of about 25 at the equator to a maximum of 65 at $90^{\circ} \mathrm{S}$. Similar results are found in Sinnhuber et al. (2006). Hence, while we have adopted the Daniel et al. (2007) value as a constant, global value, it is important to note that different values should probably be used for the midlatitudes and polar regions.

Figure 7 repeats the EESC time series from Fig. 5 for both a 3-year mean age (lower black) and a 5.5-year mean age-ofair (upper black). We also show the EESC for $\alpha=40$ (blue) and $\alpha=80$ (red). From Fig. $3 \mathrm{~b}$, we see that $\mathrm{Br}_{\mathrm{y}}$ peaks at approximately $9 \mathrm{ppt}$ for a 3 -year mean age. For the 3-year mean age-of-air, an increase or decrease of $\alpha$ by 20 will increase or decrease EESC by 172 ppt. For a 5.5-year mean age-of-air EESC is changed by 304 ppt for a change in $\alpha$ by 20. Because $\mathrm{Br}_{\mathrm{y}}$ peaks later than $\mathrm{Cl}_{\mathrm{y}}$ (see Fig. 3) an increase of $\alpha$, which increases the relative importance of $\mathrm{Br}_{\mathrm{y}}$, thereby delays the peak year of the maximum EESC. However, this shift is small. Increasing $\alpha$ from 60 to 80 delays the peak year from 2001.2 to 2001.5. The EESC recovery year is also impacted in a minor way by an increase or decrease of $\alpha$. Increasing $\alpha$ from 60 to 80 delays the 5.5-year mean age recovery year from 2067.2 to 2068.0 , and delays the 3-year mean age recovery year from 2041.2 to 2042.5 . In summary, $\alpha$ is relatively important to the peak value of EESC, but is relatively unimportant for the EESC peak year or the EESC recovery year.

It is important to realize that a change of $\alpha$ does not imply the extent to which the $\mathrm{Cl}_{\mathrm{y}}$ or $\mathrm{Br}_{\mathrm{y}}$ destruction of stratospheric ozone is changing. Rather, it only provides approximate information concerning how the relative efficiency of $\mathrm{Cl}_{\mathrm{y}}$ is changing with respect to $\mathrm{Br}_{\mathrm{y}}$ for ozone destruction. Hence, while the chlorine and bromine contributions to EESC can be directly related to $\mathrm{Cl}_{\mathrm{y}}$ and $\mathrm{Br}_{\mathrm{y}}$, the summed EESC quantity loses this direct relationship because of the introduction of the multiplicative $\alpha$ factor. Danilin et al. (1996) modeled ozone loss in the Antarctic vortex and computed $\alpha$ for a range of $\mathrm{Cl}_{\mathrm{y}}$ and $\mathrm{Br}_{\mathrm{y}}$ values. In their calculation, they showed that for a fixed amount of $\mathrm{Br}_{\mathrm{y}}, \alpha$ increases as $\mathrm{Cl}_{\mathrm{y}}$ increases, and for fixed $\mathrm{Cl}_{\mathrm{y}}, \alpha$ decreases as $\mathrm{Br}_{\mathrm{y}}$ increases. In contrast, Sinnhuber et al. (2006) calculated a slight increase in the globally averaged value of $\alpha$ when they included additional $\mathrm{Br}_{\mathrm{y}}$ in their model to account for VSLSs. We test the temporal variation of $\alpha$ by using the values from Danilin et al. (1996). We have taken their estimates of $\alpha$ and calculated $\alpha$ as a function of time for the $\mathrm{Cl}_{\mathrm{y}}$ and $\mathrm{Br}_{\mathrm{y}}$ values estimated using our age spectra and release values. Figure 7 shows EESC calculated using these time-varying $\alpha$ values 


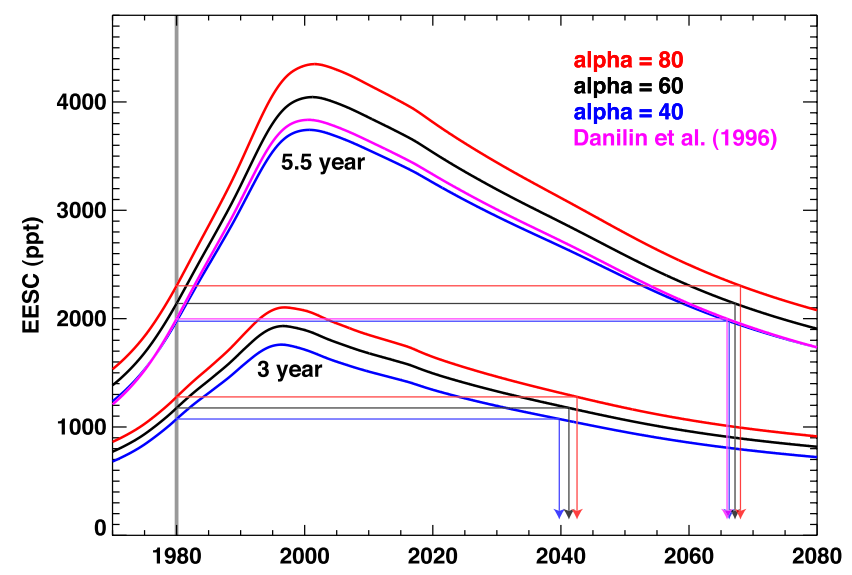

Fig. 7. EESC versus time. The upper and lower groups of curves are for a 5.5- and 3-year mean age, respectively. The red, black, and blue curves are for $\alpha=40, \alpha=60$, and $\alpha=80$, respectively. The magenta curve is estimated using a 5.5-year mean age and a varying $\alpha$ based upon Antarctic estimates from (Danilin et al., 1996). The gray vertical line indicates the reference year of 1980. The black and color horizontal and vertical lines indicate the recovery date of EESC to 1980 values.

(magenta) for a mean age of $5.5 \mathrm{y}$. Their estimated $\alpha$ has a value of 43.1 in 1980 and 41.5 in 2067. As is apparent in Fig. 7, this curve is slightly higher than the $\alpha=40$ (blue) curve. The recovery year using the $\alpha$ values from Danilin et al. (1996) is 2065.9. Using a fixed value of $\alpha=42.1$, the recovery year is 2066.4. Hence, a temporal varying $\alpha$ value leads to only modest changes in the recovery year.

\subsection{Sensitivity to halogen scenarios}

The full EESC time series depends on both the mixing ratio observations (pre-2006) and the future scenario that is estimated from projected chlorine and bromine emissions (post 2006). We have estimated the sensitivities of recovery times to variations in scenarios presented by Daniel et al. (2007). Figure 8 displays EESC versus time for three different scenarios. Scenario A1 from Daniel et al. (2007) is shown (black), again repeating our 3-year (lower) and 5.5year (upper) mean age-of-air results. Also shown are the EESC values that are derived from scenario $\mathrm{Ab}$ (blue) in the previous assessment (Montzka et al., 2003). There are two main differences between these results. First, between 2005 and 2020, the EESC from scenario A1 falls off faster than the older scenario $\mathrm{Ab}$. This results from the downward revision of methyl bromide concentrations. Second, from approximately 2020 to 2080, the EESC levels for scenario A1 are higher than the older scenario $\mathrm{Ab}$. While methyl bromide has been revised downward, CFC-11, $\mathrm{CCl}_{4}$, Halon 1211, and HCFC-22 levels have all been revised upward (Daniel et al., 2007). The main contribution to this increase is the

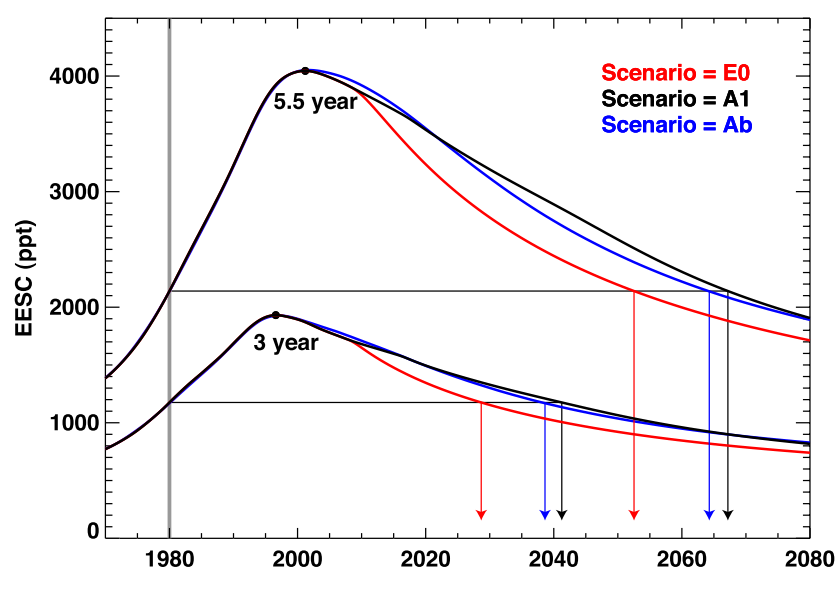

Fig. 8. EESC versus time using widths that are half of the mean ageof-air and with $\alpha=60$. The upper and lower groups of curves are for a 5.5- and 3-year mean age, respectively. The black curves indicate scenario A1 from Daniel et al. (2007), the baseline case used in Fig. 5. The red curves indicate the zero emission halogen scenario EO from Daniel et al. (2007). The blue curves indicate scenario Ab from Montzka et al. (2003). The gray vertical line indicates the reference year of 1980. The black horizontal and color vertical lines indicate the recovery date of EESC to 1980 values.

higher levels of HCFC-22 in the 2020 to 2080 period. The change from scenario Ab to A1 leads to a slight delay of recovery from 2039 to 2041.2 for the 3-year mean age and from 2064.3 to 2067.2 for the 5.5-year mean age. While the scenario revisions between Montzka et al. (2003) and Daniel et al. (2007) is substantial, the compensating changes result in modest recovery differences between the scenarios.

Figure 8 also displays EESC versus time for scenario E0 (red), which includes zero future emissions (Daniel et al., 2007). While such a scenario is purely hypothetical, it provides a useful theoretical lower limit on future ODS concentrations and a corresponding limit on recovery. For a 3-year age, the E0 recovery is 2029 as opposed to the baseline case of 2041. For a 5.5-year age, the E0 recovery is 2053 as opposed to the baseline case of 2067.

\subsection{Sensitivity to fractional release values}

The peak EESC value, the year of this peak value, and the recovery year are all dependent on the fractional release values of the various species. These sensitivities depend largely on the magnitude of the contribution of the particular halogen species to the total EESC. For example, CFC-115 had a surface mixing ratio of about 9 ppt in 2000, hence it has a small contribution to an overall 1980 EESC level of $2200 \mathrm{ppt}$ (5.5-year mean age). The peak EESC, the peak year, and the recovery year are not strongly impacted by uncertainty in the CFC-115 fractional release values. Table 1 shows the sensitivity of peak EESC and the recovery year for a 0.10 
fractional release variation centered on the assumed value of fractional release. For a 3-year mean age-of-air, CFC-11 has a fractional release of 0.47 . For a variation from 0.42 to 0.52 in fractional release, the maximum EESC changes by $79.9 \mathrm{ppt}$ and the recovery date increases by $0.47 \mathrm{y}$.

Increasing the fractional release values always increases the peak EESC value. The sensitivities of the maximum EESC value in Table 1 are proportional to the concentration of the particular species, while the sensitivities of the year of recovery are proportional to the mixing ratio difference between the value at the time of EESC recovery to the value in 1980. Because the contributions to EESC of species such as CFC-11, CFC-12, methyl chloride, and methyl bromide are large, the sensitivity of the peak EESC to release variations is also large.

In contrast to the EESC magnitude, increasing fractional release can shift the recovery date earlier (negative sensitivity) or later (positive sensitivity). A negative sensitivity example comes by increasing the fractional release of methyl chloroform. Increasing $f$ by 0.1 moves the recovery date for 3-year air 1.37 y earlier from 2041.3 to 2039.9 (0.58 y earlier for 5.5-year air). This negative sensitivity results from the methyl chloroform time history. In Fig. 2c, methyl chloroform was relatively large in 1980, peaked in early 1994, and has fallen to zero by 2041 . Increasing the fractional release for methyl chloroform by 0.1 increases 1980 EESC but does not change 2041 EESC. The total $\mathrm{Cl}_{\mathrm{y}}$ in Fig. 2d shows a recovery line drawn from the 1980 vertical line. Increasing methyl chloroform (via a fractional release increase) increases 1980 EESC without changing 2041 EESC, shifting the recovery to an earlier date. Carbon tetrachloride and methyl bromide have similar negative sensitivities for 3-yearold air.

Most species exhibit a positive increase in recovery date for an increase in fractional release. Again, this increase is sensitive to the mixing ratio difference of the particular species at the time of recovery compared to 1980 . Inspection of Figs. $2 \mathrm{~b}$ and $\mathrm{d}$ shows that CFC-12 makes a large contribution in 1980, 2041, and 2067 to the overall $\mathrm{Cl}_{\mathrm{y}}$. Increasing the CFC-12 contribution to $\mathrm{Cl}_{\mathrm{y}}$ by increasing the fractional release will push recovery further into the future because the CFC-12 contribution is larger at the time of expected recovery than it was in 1980. For a 3-year age, if the release is increased from 0.18 to 0.28 , the recovery year is increased from 2041.3 to 2043.9 (2.6 y).

We estimate the uncertainty in recovery dates using a Monte Carlo approach on the fractional release values by randomly varying all of the fractional release values for those species shown in Table 1 . The release values are altered from their standard values by adding variability with a standard deviation $\sigma=0.05$. This 0.05 standard deviation is chosen as a nominal uncertainty by inspection of the CFC-11 versus age curve shown by Schauffler et al. (2003). Fractional release values are constrained to range between 0.0 and 1.0. The uncertainty in fractional release values leads to a moderate uncertainty in the year of recovery. For a 3-year mean age, the $95 \%$ confidence limits on the 2041.3 recovery date vary from 2036.1 to 2045.1 ( $\sigma=2.2$ y). For a 5.5-year mean age, the $95 \%$ confidence limits on the 2067.2 recovery date are from 2066.0 to 2069.4 ( $\sigma=0.86 \mathrm{y}$ ).

The variation in the recovery date $\delta y_{i}=y^{\prime}-y$ for a particular species due to a prescribed variation in fractional release $\delta f_{i}=f^{\prime}-f$ can be theoretically derived from Eq. (1). $\operatorname{EESC}_{i}^{\prime}(y)-\operatorname{EESC}_{i}(y)=n_{i} \delta f_{i} \rho_{i}(y)$ is the difference in EESC for a given year $y$. Using $\operatorname{EESC}_{i}^{\prime}(1980)=\operatorname{EESC}_{i}^{\prime}\left(y+\delta y_{i}\right)=\operatorname{EESC}_{i}^{\prime}(y)+\partial \operatorname{EESC}_{i}^{\prime} / \partial t \delta y_{i}$ (from a Taylor expansion), and noting that $\operatorname{EESC}_{i}(y)=\operatorname{EESC}_{i}(1980)$ and that $\partial \mathrm{EESC} / \partial t \approx$ $\partial \mathrm{EESC}_{i}^{\prime} / \partial t$, gives

$$
\begin{aligned}
\partial \mathrm{EESC} / \partial t \delta y= & \operatorname{EESC}_{i}^{\prime}(1980)-\operatorname{EESC}_{i}^{\prime}(y) \\
= & {\left[\operatorname{EESC}_{i}^{\prime}(1980)-\operatorname{EESC}_{i}(1980)\right] } \\
& -\left[\operatorname{EESC}_{i}^{\prime}(y)-\operatorname{EESC}_{i}(y)\right] \\
= & n_{i} \delta f_{i} \rho_{i}(1980)-n_{i} \delta f_{i} \rho_{i}(y)
\end{aligned}
$$

Solving for $\delta y_{i}$ gives

$\delta y_{i}=-\frac{\delta f_{i} n_{i}\left[\rho_{i}(y)-\rho_{i}(1980)\right]}{\partial \mathrm{EESC} / \partial t}$,

A comparison of recovery year sensitivity to individual fractional release values can be seen in Table 1. In general, the magnitude of the sensitivity is smaller for a 5.5-year mean age than for a 3-year mean age.

The smaller uncertainty in the recovery for the 5.5-year mean age-of-air results from the larger rate of EESC decreases at the time of recovery $(\partial \mathrm{EESC} / \partial t)$. Inspection of Fig. 5 reveals that EESC is changing at a rate of about -20 ppt y $^{-1}$ for 5.5-year air in about 2067, while the decline

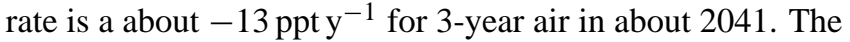
sensitivity is inversely proportional to this decline rate, and so the sensitivity decreases as mean age-of-air increases.

\subsection{Sensitivity to recovery start date}

In all figures herein, the recovery dates indicated are determined from the EESC level in 1980. This 1980 value is chosen as a useful mark because the amount of ozone depletion at midlatitudes and in the Antarctic vortex was relatively small. Hence, 1980 is the year often considered in previous work (Madronich et al., 1999; Chipperfield et al., 2003; Montzka et al., 2003; Newman et al., 2003; Bodeker et al., 2007; Daniel et al., 2007) and has been adopted herein for our standard calculations.

The recovery date is very sensitive to this starting date. In spite of the previous justification for the choice of 1980, the ODS level in 1980 should not be considered as the pre-ozone depletion level; for example, for a 3-year mean age, EESC had more than doubled between 1950 and 1980 (Fig. 3). EESC increased rapidly over the 1970s (Fig. 5), and Farman et al. (1985) showed that some ozone loss had occurred as 


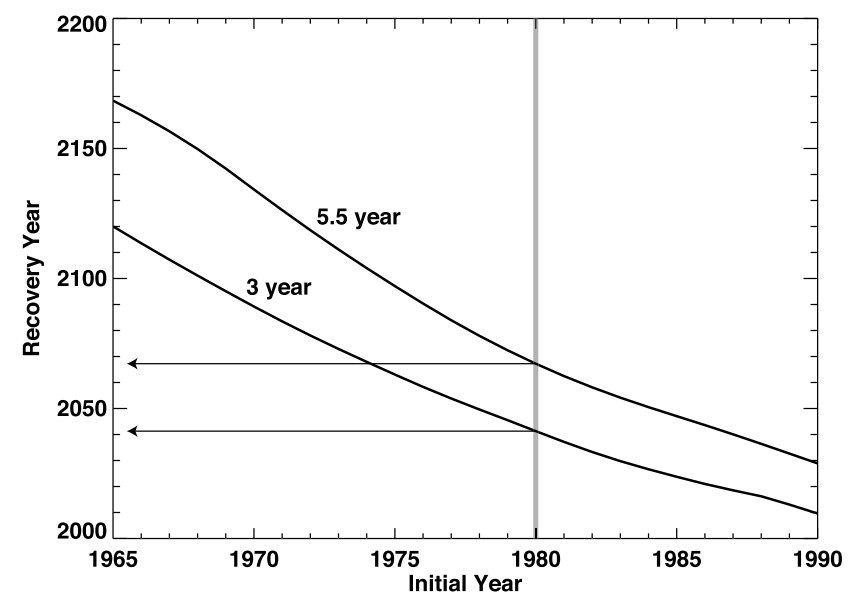

Fig. 9. Recovery year as a function of initial year. The upper and lower curves are for a 5.5-year and a 3-year mean age-of air, respectively. The gray vertical line indicates the reference year of 1980 . The black horizontal lines indicate the recovery date of EESC to 1980 values.

early as 1975 over Antarctica. If the start date for ozone loss is set to 1975 rather than 1980 then the recovery is pushed from 2041.3 to 2063.0 for a 3-year mean age and from 2067.2 to 2097.0 for a 5.5-year mean age. Figure 9 displays the sensitivity to recovery date. A shift of one year changes the recovery by approximately ten years. However, this result does not change the fact that the date corresponding to 1980 EESC levels still represents a time when ozone loss due to ODSs, in the absence of other atmospheric changes, should be relatively small compared to the losses of the past decade or so.

5.7 Sensitivity to temporal changes of age-of-air and fractional release

In the above calculations we have assumed that the mean age-of-air is constant in time. However, model simulations suggest that the mean age may decrease with time as a result of an accelerated mean circulation from climate change. Austin and Li (2006) show an age decrease at 60-90 $\mathrm{N}$ and $35 \mathrm{hPa}$ of about $0.15 \mathrm{y}$ per decade. In addition to decreasing mean age, an accelerated circulation changes the fractional release values. A faster circulation will both decrease the age and shift the fractional release values to higher numbers for a given age, while a slower circulation has the opposite effect. For example, increasing vertical motion in the stratospheric tropical pipe will decrease the mean age as the air is cycled faster. In contrast, the CFC photolysis rates in the mid to upper stratosphere are only modestly affected by circulation changes (primarily via ozone changes in the upper stratosphere). Hence, the fractional release value remains the same, while the mean age decreases. For fractional release

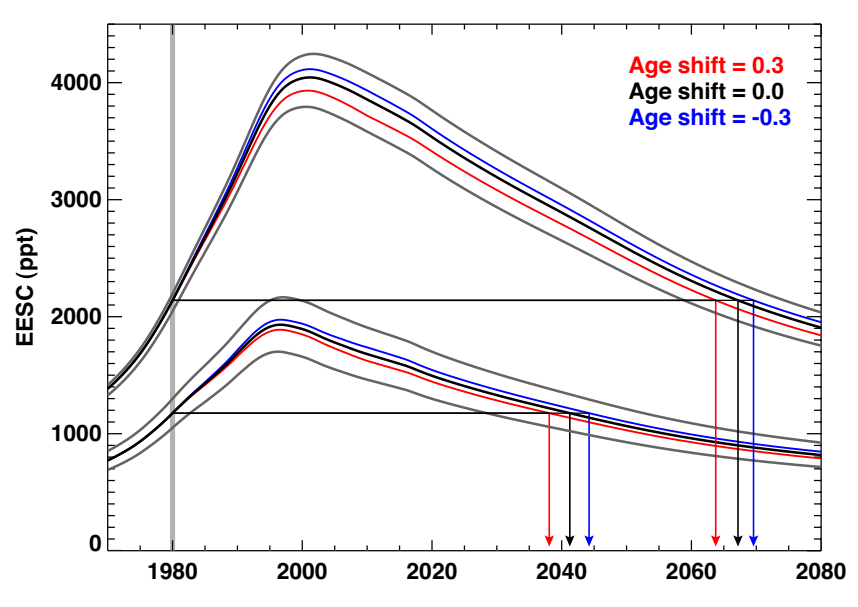

Fig. 10. EESC versus time. The black curves indicate EESC for 3.0 and 5.5 y (i.e., no age shift). The gray curves indicate ages of $\pm 0.3 \mathrm{y}$ about the upper and lower curves that are centered on $5.5 \mathrm{y}$ and $3 y$, respectively. The red curves are derived by linearly changing the age from $3.0 \mathrm{y}$ to $3.3 \mathrm{y}$ and from $5.5 \mathrm{y}$ to $5.8 \mathrm{y}$ between 1980 and 2010, with systematic fractional release changes that are consistent with the age changes. The blue lines are similarly derived, but the mean age is decreased from $3.0 \mathrm{y}$ to $2.7 \mathrm{y}$ and from $5.5 \mathrm{y}$ to $5.2 \mathrm{y}$ with coherent fractional release changes. The gray vertical line indicates the reference year of 1980. The black horizontal and colored vertical lines indicate the recovery date of EESC to 1980 values.

versus age curves (e.g., Fig. 11c of Schauffler et al., 2003), the values are shifted over to younger ages. For a fixed mean age, this translates into an increased fractional release value. Thus, we cannot assume that either mean age-of-air or fractional release values are constant in time.

We test the sensitivity of EESC to temporal changes in the mean age by linearly varying the mean age by $0.3 \mathrm{y}$ over the 1980 to 2010 period. This change, while significant, is still smaller than the decrease calculated by Austin and Li (2006) for the polar lower stratosphere. To calculate the coherent variation of release values, we have drawn upon a time series of CFC-11, CFC-12 and mean age-of-air from the Goddard Earth Observing System (GEOS-4) chemistry/climate model (CCM) (Stolarski et al., 2006b). Based upon the GEOS4 model temporal changes of fractional release values, we coherently increase release values by $1 \%$ for each 0.1 -year change of mean age.

Figure 10 shows EESC for an increase of age from $3.0 \mathrm{y}$ to $3.3 \mathrm{y}$ (lower red) and $5.5 \mathrm{y}$ to $5.8 \mathrm{y}$ (upper red), and a decrease of age from $3.0 \mathrm{y}$ to $2.7 \mathrm{y}$ (lower blue) and from $5.5 \mathrm{y}$ to $5.2 \mathrm{y}$ (upper blue). The 0.3-year age change alters the EESC behavior and recovery date. Reducing the age from $3.0 \mathrm{y}$ to 2.7 y accelerates recovery from 2041.3 to 2038.1 , and reducing the age from $5.5 \mathrm{y}$ to $5.2 \mathrm{y}$ accelerates recovery from 2067.2 to 2063.8 . 
Table 2. Estimated uncertainties for recovery dates with 3-year and 5.5-year mean age-of-air. The lower and upper values are of the recovery year for each side of the two-sided $95 \%$ confidence limits, based on the prescribed uncertainties. The years in the header are the standard recovery years corresponding to the mean age-of-air.

\begin{tabular}{|c|c|c|c|c|c|c|c|}
\hline \multirow[t]{2}{*}{ Parameter } & \multirow[t]{2}{*}{ Prescribed uncertainty } & \multicolumn{3}{|c|}{$\Gamma=3$ y $(2041.3)$} & \multicolumn{3}{|c|}{$\Gamma=5.5$ y $(2067.2)$} \\
\hline & & $\begin{array}{c}\sigma \\
(\mathrm{y})\end{array}$ & $\begin{array}{l}\text { Lower } \\
\text { (y) }\end{array}$ & $\begin{array}{l}\text { Upper } \\
\text { (y) }\end{array}$ & $\begin{array}{c}\sigma \\
(\mathrm{y})\end{array}$ & $\begin{array}{l}\text { Lower } \\
\text { (y) }\end{array}$ & $\begin{array}{c}\text { Upper } \\
(\mathrm{y})\end{array}$ \\
\hline Mean age $(\Gamma)$ & $\pm 0.3 \mathrm{y}$ & 2.64 & 2036.1 & 2046.5 & 4.09 & 2059.2 & 2074.4 \\
\hline Width $(\Delta)$ & $\Gamma / 2 \pm 30 \%$ & 0.29 & 2040.6 & 2041.7 & 1.01 & 2064.9 & 2068.8 \\
\hline$\alpha$ & $60 \pm 15$ & 1.06 & 2038.9 & 2043.1 & 0.65 & 2065.8 & 2068.4 \\
\hline Fractional release $(f)$ & $\pm 5 \%$ & 2.23 & 2036.8 & 2045.4 & 0.88 & 2065.9 & 2069.4 \\
\hline Start date & $1980 \pm 0.5 \mathrm{y}$ & 2.10 & 2037.2 & 2045.4 & 2.48 & 2062.5 & 2072.2 \\
\hline$\Gamma(t)+$ red noise & $\approx 0.3 \mathrm{y}$ & 4.36 & 2032.3 & 2048.7 & 1.99 & 2063.4 & 2071.0 \\
\hline Total & & 6.28 & 2027.7 & 2052.2 & 5.50 & 2056.3 & 2077.6 \\
\hline
\end{tabular}

The above changes in recovery date, at first glance, appear to be slightly inconsistent with the earlier analysis of sensitivity to mean age, where a change of $0.3 \mathrm{y}$ resulted in a 3-year shift in the recovery date. As noted earlier from Fig. 4c, the EESC decreases at a relatively regular rate in the period after about 2001 for a constant mean age-of-air. An acceleration of the circulation decreases the age but increases the fractional release values. Overall, an acceleration in the circulation will act to decrease the EESC.

Random variations of mean age on a decadal time scale add uncertainty to recovery estimates in addition to secular trends. In order to estimate the impact of decadal variations, we again use the time series of mean age-of-air from the GEOS-4 CCM (Stolarski et al., 2006b). In this CCM run, the mean age-of-air shows decadal variations on the order of $0.1-0.2 \mathrm{y}$. To simulate this effect, we generate artificial age-of-air time series using the statistical characteristics of the model's age-of-air time series. In particular, we take detrended polar and midlatitude time series of age-of-air from model runs extending to 2100 , compute a power spectrum from those time series, and fit a power law to those analyzed time series. We then add noise to these power law fits using a gamma distribution, and randomly vary the temporal phase of each frequency over the period from 1950 to 2100 . These random age-of-air time series lead to EESC variation in both 1980 and at the recovery period. For the 3-year mean age-ofair EESC the standard uncertainty, $\sigma$, in the year of recovery is $4.4 \mathrm{y}$, while for the 5.5-year mean age-of-air $\sigma=2.0 \mathrm{y}$.

\subsection{Combined uncertainties}

The previous sections discussed EESC sensitivities. In this section we perform Monte Carlo simulations to calculate the recovery date uncertainties assuming future halocarbon abundances in the A1 scenario of Daniel et al. (2007) are accurate (summarized in Table 2). The first row summarizes the uncertainty in the mean age-of-air, $\Gamma$. Inspection of Fig. 6 from Andrews et al. (2001) suggests $\sigma \approx 0.3$ y. We vary the age with $\sigma=0.3 \mathrm{y}$ using a Monte Carlo technique in our EESC calculations while holding all other variables fixed, with the exception that fractional releases vary with the mean age. This Monte Carlo technique yields a probability distribution function (PDF) with $\sigma=2.64 \mathrm{y}$ for 3-year old air and $\sigma=4.09 \mathrm{y}$ for 5.5 -year old air. The 3-year 95\% confidence limits for the 2041.3 recovery are from 2036.1 to 2046.5, while the 5.5-year limits are 2059.2 to 2074.4.

We similarly use the Monte Carlo technique to calculate PDFs for $\Delta, \alpha, f$, and the start date. The uncertainty on $\Delta$ is estimated from Andrews et al. (2001) and Schoeberl et al. (2005), on $\alpha$ is from Daniel et al. (1999), on the start date is from Fioletov et al. (2002), on $f$ is from Schauffler et al. (2003), and on the temporal variations in $\Gamma$ is from the analysis of the GEOS-4 CCM model output (Stolarski et al., 2006b). In the case of the age temporal variations $(\Gamma(t)+$ red noise), we have not coherently adjusted the fractional release values with mean age, such that this variance is an upper limit.

The total uncertainty is calculated by varying all of the factors listed in Table 2. For EESC with a 3-year mean ageof-air (recovery in 2041.3), the distribution of recovery dates is somewhat skewed, with $95 \%$ confidence limits of 2027.7 and 2052.2. For the Antarctic EESC with a 5.5-year mean age-of-air (recovery in 2067.2), the 95\% confidence limits are 2056.3 and 2077.6. This 5.5-year uncertainty is dominated by the uncertainty in value of the mean age.

\section{Summary and discussion}

EESC is an important quantity for estimating the effect of surface ODS emissions and concentrations on stratospheric chlorine and bromine levels, and can provide insight into peak $\mathrm{Cl}_{\mathrm{y}}$ and $\mathrm{Br}_{\mathrm{y}}$ levels in the stratosphere and into future ozone recovery. In this paper we have described a 
reformulation of the technique for estimating EESC. This reformulation uses both fractional release values that are dependent upon mean age-of-air, and an age spectrum to represent the transport time lag between the tropospheric levels of ODSs. In addition to EESC, this reformulation also provides quantitative estimates of total inorganic chlorine, bromine, and fluorine that are dependent on the mean age-of-air.

Using this new formulation we have estimated new ODS recovery dates for the stratosphere. We estimate, given the future halocarbon abundances projected in scenario A1 of Daniel et al. (2007), that midlatitude recovery will occur in 2041 while the Antarctic region will recover in 2067. Midlatitude air is characterized by an age-of-air of approximately $3 \mathrm{y}$, while Antarctic lower stratospheric air has a mean age of approximately $5.5 \mathrm{y}$. We have followed Daniel et al. (2007) by using a bromine scaling factor of 60 and their scenario A1. This contrasts with the Daniel et al. (2007) estimates of 2048.6 and 2064.7. The differences in these estimates are primarily due to differences in the fractional release values of a few ODSs. The $95 \%$ confidence limits for the midlatitude 2041 recovery are 2027.7 and 2052.2, while the Antarctic limits are 2056.3 and 2077.6.

Newman et al. (2006) estimated that the ozone hole's area would fully recover (decrease to a zero size) by 2068. This estimate was based upon a 5.5-year mean age-of-air, scenario $\mathrm{Ab}$ of Montzka et al. (2003), and an empirical estimate that the ozone hole had an initial zero size in mid-1979, not 1980. In that study, they confined the observations to the vortex where age-of-air ought to be relatively uniform and a constant value as a function of time. Using the new Scenario A1 from Daniel et al. (2007) we now estimate that the ozone hole's area recovery will shift by two years, from 2068 to 2070.

We have also explored the sensitivity of EESC to a number of parameters. These parameters include mean age-ofair, age spectrum width, bromine efficiency for ozone destruction versus chlorine, fractional release, starting date for ODS losses, and temporal changes of mean age-of-air and fractional release values. The recovery dates for EESC are primarily dependent upon the mean age-of-air and trends in the mean age-of-air. For example, the Antarctic EESC recovers at a later date than the midlatitude EESC because the air in the Antarctic stratosphere is older. A temporal trend in mean age with a coherent variation of release values also can impact recovery. Austin and Li (2006) estimated that Arctic stratospheric air $\left(60-90^{\circ} \mathrm{N}, 35 \mathrm{hPa}\right)$ would become younger by approximately $0.5 \mathrm{y}$ between 1980 and 2040 , while upper stratospheric tropical air $\left(20^{\circ} \mathrm{S}-20^{\circ} \mathrm{N}, 1.3 \mathrm{hPa}\right)$ would become younger by $0.8 \mathrm{y}$. If air in the midlatitude stratosphere becomes younger by $0.3 \mathrm{y}$, we estimate that recovery could be advanced by as much as $3-4 \mathrm{y}$.

The strong dependence of EESC on mean age-of-air exposes a crucial assumption that underlies many trend studies and future EESC projections: viz., mean age-of-air and fractional release values are constant over the ozone data record.
A shift in mean age can significantly impact interpretation of ozone trends and EESC values. For a 3-year mean age, a \pm 0.3 -year shift in mean age results in a \pm 9 -year shift in recovery to 1980 values and nearly a $230 \mathrm{ppt}(12 \%)$ change in the peak EESC value. In ozone trend studies, it has been assumed that EESC has a fixed shift with respect to the tropospheric values (typically $3 \mathrm{y}$ ). Changes in the circulation will cause both changes in the advection of ozone and age-ofair, and therefore the EESC of the lower stratosphere. EESC variations resulting from age-of-air variation have the potential to lead to large variations of ozone.

The analysis of ozone trends also requires a careful consideration of sampling issues to insure that the fractional chlorine and bromine release values can be accurately parameterized. This can be accomplished by ensuring that the mean age-of-air is either large (greater than $5.8 \mathrm{y}$ ) or is relatively constant over the ozone observation record. Sampling of ozone near the edge of the polar vortex is particularly susceptible to such a problem because of the large gradient of age-of-air at the polar vortex edge. Great caution must be exercised in interpreting ozone trends because of the variation of age-of-air spatially and over the observation time period.

The EESC estimates have proven extremely useful for estimating recovery and for exploring various emission scenarios. However, the use of EESC is limited by the assumptions that underlie the calculations. First, estimates of fractional release and mean age-of-air are largely calculated from midlatitude and Arctic observations in the lower stratosphere during the last 15 years. Models show that release values are also a function of altitude and that the mean ages in the stratosphere may be changing. Second, we have assumed that the fractional release observationally derived functions are also fixed in time. This assumption cannot be strictly justified because of both circulation and chemistry changes in the future. Finally, while EESC is a convenient parameter for recovery estimates, it is not equivalent to ozone, and it does not include the fully interactive elements of a coupled climate/chemistry model.

Acknowledgements. This research was funded under the NASA Atmospheric Chemistry, Modeling, and Analysis Program. The comments and discussions with A. Douglass, S. Montzka, and R. Stolarski were extremely helpful.

Edited by: M. Dameris

\section{References}

Anderson, J., Russell III, J. M., Solomon, S., and Deaver, L. E.: Halogen Occultation Experiment confirmation of stratospheric chlorine decreases in accordance with the Montreal Protocol, J. Geophys. Res., 103(D4), 4483-4490, doi:10.1029/1999JD901075, 2000.

Andrews, A. E., Boering, K. A., Daube, B. C., Wofsy, S. C., Loewenstein, M., Jost, H., Podolske, J. R., Webster, C. R., Herman, R. L., Scott, D. C., Flesch, G. J., Moyer, E. J., 
Elkins, J. W., Dutton, G. S., Hurst, D. F., Moore, F. L., Ray, E. A., Romashkin, P. A., and Strahan, S. E.: Mean ages of stratospheric air derived from in situ observations of $\mathrm{CO}_{2}$, $\mathrm{CH}_{4}$, and $\mathrm{N}_{2} \mathrm{O}$, J. Geophys. Res., 106(D23), 32 295-32 314, doi:10.1029/2001JD000465, 2001.

Austin, J. and Li, F.: On the relationship between the strength of the Brewer-Dobson circulation and the age of stratospheric air, Geophys. Res. Lett., 33, L17807, doi:10.1029/2006GL026867, 2006.

Bodeker, G. E., Waugh, D. W., Akiyoshi,, H., Braesicke, P., Eyring, V., Fahey, D. W., Manzini, E., Newchurch, M. J., Portmann, R. W., Robock, A., Shine, K. P., Steinbrecht, W., and Weatherhead. E. C.: The ozone layer in the $21^{\text {st }}$ Century, Chapter 6 in World Meteorological Organization: Scientific assessment of ozone depletion: 2006, Global Ozone Research and Monitoring Project - Report No. 50, Geneva, 43 pp., 2007.

Chipperfield, M. P., Randel, W. J., Bodeker, G. E., Dameris, M., Fioletov, V. E., Friedl, R. R., Harris, N. R. P., Logan. J. A., McPeters, R. D., Muthama, N. J., Peter, T., Shepherd, T. G., Shine, K .P., Solomon, S., Thomason, L. W., and Zawodny, J. M.: Global ozone: Past and future, Chapter 4 in World Meteorological Organization: Scientific assessment of ozone depletion: 2002, Global Ozone Research and Monitoring Project - Report No. 47, Geneva, 91 pp., 2003.

Clerbaux, C., Cunnold, D. M., Anderson, J., Engel, A., Fraser, P. J., Mahieu, E., Manning, A., Miller, J., Montzka, S. A., Nassar, R., Prinn, R., Reimann, S., Rinsland, C. P., Simmonds, P., Verdonik, D., Weiss, R., Wuebbles, D., and Yokouchi, Y.: Long-lived Compounds, Chapter 1 in World Meteorological Organization: Scientific assessment of ozone depletion: 2006, Global Ozone Research and Monitoring Project - Report No. 50, Geneva, 63 pp., 2007.

Daniel, J. S., Solomon, S., and Albritton, D. L.: On the evaluation of halocarbon radiative forcing and global warming potentials, J. Geophys. Res., 100(D1), 1271-1285, doi:10.1029/94JD02516, 1995.

Daniel, J. S., Solomon, S., Portmann, R. W., and Garcia, R. R.: Stratospheric ozone destruction: The importance of bromine relative to chlorine, J. Geophys. Res., 104(D19), 23 871-23 880, doi:10.1029/1999JD900381, 1999.

Daniel, J. S., Velders, G. J. M., Douglass, A. R., Forster, P. M. D., Hauglustaine, D. A., Isaksen, I. S. A., Kuijpers, L. J. M., McCulloch, A., and Wallington, T. J.: Halocarbon scenarios, ozone depletion potentials, and global warming potentials, Chapter 8 in World Meteorological Organization: Scientific assessment of ozone depletion: 2006, Global Ozone Research and Monitoring Project - Report No. 50, Geneva, 39 pp., 2007.

Danilin, M. Y., Sze, N.-D., Ko, M. K., Rodriguez, J. M., and Prather, M. J.: Bromine-chlorine coupling in the Antarctic ozone hole, Geophys. Res. Lett., 23(2), 153-156, doi:10.1029/95GL03783, 1996.

Dhomse, S., Weber, M., Wohltmann, I., Rex, M., and Burrows, J. P.: On the possible causes of recent increases in northern hemispheric total ozone from a statistical analysis of satellite data from 1979 to 2003, Atmos. Chem. Phys., 6, 1165-1180, 2006, http://www.atmos-chem-phys.net/6/1165/2006/.

Dorf, M., Bösch, H. Butz, A., Camy-Peyret, C., Chipperfield, M. P., Engel, A., Goutail, F., Grunow, K., Hendrick, F., Hrechanyy, S., Naujokat, B., Pommereau, J.-P., Van Roozendael, M., Sioris,
C., Stroh, F., Weidner, F., and Pfeilsticker, K.: Balloonborne stratospheric $\mathrm{BrO}$ measurements: comparison with Envisat/SCIAMACHY BrO limb profiles, Atmos. Chem. Phys., 6, 2483-2501, 2006, http://www.atmos-chem-phys.net/6/2483/2006/.

Farman, J. C., Gardiner, B. G., and Shanklin, J. D.: Large losses of total ozone in Antarctica reveal seasonal $\mathrm{ClO}_{\mathrm{x}} / \mathrm{NO}_{\mathrm{x}}$ interaction, Nature, 315, 207-210, doi:10.1038/315207a0, 1985.

Fioletov, V. E., Bodeker, G. E., Miller, A. J., McPeters, R. D., and Stolarski, R.: Global and zonal total ozone variations estimated from ground-based and satellite measurements, J. Geophys. Res., 107(D22), 4647, doi:10.1029/2001JD001350, 2002.

Fleming, E. L., Jackman, C. H., Stolarski, R. S., and Considine, D. B.: Simulation of stratospheric tracers using an improved empirically based two-dimensional model transport formulation, J. Geophys. Res., 104(D1), 1759-1766, doi:10.1029/1998JD10028, 1999.

Guillas, S., Tiao, G. C., Wuebbles, D. J., and Zubrow, A.: Statistical diagnostic and correction of a chemistry-transport model for the prediction of total column ozone, Atmos. Chem. Phys., 6, 525537, 2006, http://www.atmos-chem-phys.net/6/525/2006/.

Law, K. S., Sturges, W. T., Blake, D. R., Blake, N. J., Burkholder, J. B., Butler, J. H., Cox, R. A., Haynes, P. H., Ko, M. K. W., Kreher, K., Mari, C., Pfeilsticker, K., Plane, J. .M. C., Salawitch, R. J., Schiller, C., Sinnhuber, B.-M., von Glasow, R., Warwick, N. J., Wuebbles, D. J., and Yvon-Lewis, S. A.: Halogenated very short-lived substances, Chapter 2 in World Meteorological Organization: Scientific assessment of ozone depletion: 2006, Global Ozone Research and Monitoring Project - Report No. 50, Geneva, 57 pp., 2007.

Madronich, S., Velders, G. J. M., Daniel, J. S., Lal, M., McCulloch, A., and Slaper, H.: Halocarbon scenarios for the future ozone layer and related consequences, Chapter 11 in World Meteorological Organization: Scientific assessment of ozone depletion: 1998, Global Ozone Research and Monitoring Project - Report No. 44, Geneva, 38 pp., 1999.

Montzka, S. A., Butler, J. H., Myers, R. C., Thompson, T. M., Swanson, T. H., Clarke, A. D., Lock, L. T., and Elkins, J. W.: Decline in the tropospheric abundance of halogen from halocarbons: Implications for stratospheric ozone depletion, Science, 272, 1318-1322, doi:10.1126/science.272.5266.1318, 1996.

Montzka, S. A., Fraser, P. J., Butler, J. H., Connell, P. S., Cunnold, D. M., Daniel, J. S., Derwent, R. G., Lal, S., McCulloch, A., Oram, D. E., Reeves, C. E., Sanhueza, E., Steele, L. P., Velders, G. J. M., Weiss, R. F., and Zander, R. J.: Controlled substances and other source gases, Chapter 1 in World Meteorological Organization: Scientific assessment of ozone depletion: 2002, Global Ozone Research and Monitoring Project - Report No. 47, Geneva, 83 pp., 2003.

Newchurch, M. J., Yang, E.-S., Cunnold, D. M., Reinsel, G. C., Zawodny, J. M., , and Russel III, J. M.: Evidence for slowdown in stratospheric ozone loss: First stage of ozone recovery, J. Geophys. Res., 108(D16), 4507, doi:10.1029/2003JD003471, 2003.

Newman, P. A., Pyle, J. A., Austin, J., Braathen, G. O., Canziani, P. O., Carslaw, K. S., Forster, P. M. de F., Godin-Beekman, S., Knudsen, B. M., Kreher, K., Nakane, H., Pawson, S., Ramaswamy, V., Rex, M., Salawitch, R. J., Shindell, D. T., Tabazadeh, A., and Toohey, D. W.: Polar stratospheric ozone: 
Past and future, Chapter 3 in World Meteorological Organization: Scientific assessment of ozone depletion: 2002, Global Ozone Research and Monitoring Project - Report No. 47, Geneva, 104 pp., 2003.

Newman, P. A., Nash, E. R., Kawa, S. R., Montzka, S. A., and Schauffler, S. M.: When will the Antarctic ozone hole recover?, Geophys. Res. Lett., 33, L12814, doi:10.1029/2005GL025232, 2006.

Prinn, R. G., Zander, R, Cunnold, D. M., Elkins, J. W., Engel, A., Fraser, P. J., Gunson, M. R., Ko, M. K. W., Mahieu, E., Midgley, P. M., Russell III, J. M., Volk, C. M., and Weiss, R. F.: Long-lived ozone-related compounds, Chapter 1 in World Meteorological Organization: Scientific assessment of ozone depletion: 1998, Global Ozone Research and Monitoring Project - Report No. 44, Geneva, 54 pp., 1999.

Sarma, K. M. and Bankobeza, G. M. (Eds.): The Montreal protocol on substances that deplete the ozone layer, United Nations Environment Programme, Nairobi, Kenya, 2000.

Schauffler, S. M., Atlas, E. L., Donnelly, S. G., Andrews, A., Montzka, S. A., Elkins, J. W., Hurst, D. F., Romashkin, P. A., Dutton, G. S., and Stroud, V.: Chlorine budget and partitioning during the Stratospheric Aerosol and Gas Experiment (SAGE) III Ozone Loss and Validation Experiment (SOLVE), J. Geophys. Res., 108(D5), 4173, doi:10.1029/2001JD002040, 2003.

Schoeberl, M. R., Douglass, A. R., Polansky, B., Boone, C., Walker, K. A., and Bernath, P.: Estimation of stratospheric age spectrum from chemical tracers, J. Geophys. Res., 110, D21303, doi:10.1029/2005JD006125, 2005.

Sinnhuber, B.-M., Sheode, N., Sinnhuber, M., Chipperfield, M. P., and Feng, W.: The contribution of anthropogenic bromine emissions to past stratospheric ozone trends: a modelling study, Atmos. Chem. Phys. Discuss., 6, 6497-6524, 2006,

http://www.atmos-chem-phys-discuss.net/6/6497/2006/.

Solomon, S. and Albritton, D.: Time-dependent ozone depletion potentials for short- and long-term forecasts, Nature, 357, 3337, doi:10.1038/357033a0, 1992.

Solomon, S., Wuebbles, D., Isaksen, I., Kiehl, J. Lal, M., Simon, P., and Sze, N.-D.: Ozone depletion potentials, global warming potentials, and future chlorine/bromine loading, Chapter 13 in World Meteorological Organization: Scientific assessment of ozone depletion: 1994, Global Ozone Research and Monitoring Project - Report No. 37, Geneva, 36 pp., 1995.
Stolarski, R. S., Douglass, A. R., Steenrod, S., and Pawson, S.: Trends in stratospheric ozone: Lessons learned from a 3D chemical transport model, J. Atmos. Sci., 63, 1028-1041, doi:10.1175/JAS3650.1, 2006a.

Stolarski, R. S., Douglass, A. R., Gupta, M., Newman, P. A., Pawson, S., Schoeberl, M. R., and Nielsen, J. E.: An ozone increase in the Antarctic summer stratosphere: A dynamical response to the ozone hole, Geophys. Res. Lett., 33, L21805, doi:10.1029/2006GL026820, 2006b.

Volk, C. M., Elkins, J. W., Fahey, D. W., Dutton, G. S., Gilligan, J. M., Loewenstein, M., Podolske, J. .R., Chan, K. R., and Gunson, M. R.: Evaluation of source gas lifetimes from Stratospheric observations, J. Geophys. Res., 102(D21), $25543-$ 25 564, doi:10.1029/97JD02215, 1997.

Waugh, D. W. and Hall, T. M.: Age of stratospheric air: Theory, observations, and models, Rev. Geophys., 40(4), 1010, doi:10.1029/2000RG000101, 2002.

World Meteorological Organization: Scientific assessment of ozone depletion: 1994, Global Ozone Research and Monitoring Project - Report No. 37, Geneva, 1995.

World Meteorological Organization: Scientific assessment of ozone depletion: 1998, Global Ozone Research and Monitoring Project - Report No. 44, Geneva, 1999.

World Meteorological Organization: Scientific assessment of ozone depletion: 2002, Global Ozone Research and Monitoring Project - Report No. 47, Geneva, 2003.

World Meteorological Organization: Scientific assessment of ozone depletion: 2006, Global Ozone Research and Monitoring Project - Report No. 50, Geneva, 2007.

Yang, E.-S., Cunnold, D. M., Newchurch, M. J., and Salawitch, R. J.: Change in ozone trends at southern high latitudes, Geophys. Res. Lett., 32, L12812, doi:10.1029/2004GL022296, 2005. 